\title{
The Neuroprotective Effects of Cannabis-Derived Phytocannabinoids and Resveratrol in Parkinson's Disease: A Systematic Review of Pre-clinical Studies
}

\author{
Samay Prakash ${ }^{1}$ and Wayne G. Carter ${ }^{*}$ \\ 1 Samay Prakash; School of Medicine, University of Nottingham, Royal Derby Hospital Centre, Derby, DE22 \\ 3DT.UK; Email: mzysp8@nottingham.ac.uk. \\ 1 Dr Wayne Grant Carter; School of Medicine, University of Nottingham, Royal Derby Hospital Centre, \\ Derby, DE22 3DT.UK. \\ *Corresponding author: Tel: +44(0)1332 724738; Fax: +44(0)1332 724626 \\ Email: Wayne.Carter@nottingham.ac.uk.
}

\begin{abstract}
Currently, there are no pharmacological treatments able to reverse nigral degeneration in Parkinson's disease (PD), hence the unmet need for the provision of neuroprotective agents. Cannabis-derived phytocannabinoids (CDCs) and resveratrol (RSV) may be useful neuroprotective agents for PD due to their anti-oxidative and anti-inflammatory properties. To evaluate this, we undertook a systematic review of the scientific literature to assess the neuroprotective effects of CDCs and RSV treatments in pre-clinical in vivo animal models of PD. The literature databases MEDLINE, EMBASE, PsychINFO, PubMed and Web of Science core collection were systematically searched to cover relevant studies. A total of 1034 publications were analyzed, of which 18 met the eligibility criteria for this review. Collectively, the majority of neurotoxin-induced PD rodent studies demonstrated that treatment with CDCs or RSV produced a significant improvement in motor function and mitigated the loss of dopaminergic neurons. Biochemical analysis of rodent brain tissue suggested that neuroprotection was mediated by anti-oxidative, anti-inflammatory, and anti-apoptotic mechanisms. This review highlights the neuroprotective potential of CDCs and RSV for in vivo models of PD, and therefore suggests their potential translation to human clinical trials to either ameliorate PD progression and/or be implemented as a prophylactic means to reduce the risk of development of PD.
\end{abstract}

Keywords: Cannabinoids; Cannabis-derived phytocannabinoids; Neuroprotection; Resveratrol; Parkinson's disease.

\section{Introduction}

Parkinson's Disease (PD) is a neurodegenerative motor disorder that primarily affects the elderly. PD is progressive, and patients typically display a clinical triad of motor symptoms that are postural rigidity, bradykinesia and resting tremor [1]. Approximately 1\% of the population over the age of 70 and an estimated 6.2 million individuals worldwide are affected by PD, and this is expected to increase yearly in line with a burgeoning geriatric population [2-4]. PD is characterized histopathologically by the loss of dopaminergic neurons within the substantia nigra pars compacta (SNpc) and accumulation of protein aggregates including $\alpha$-synuclein within Lewy-bodies (LBs) [5-8]. The oligomeric and aggregated forms of $\alpha$-synuclein can be neurotoxic and can promote loss of dopaminergic neurons [5-8]. PD is primarily an idiopathic disease, for which age is the major risk factor [9]. However, other risk factors associated with lifestyle and environmental exposures, such as alcohol intake and pesticide exposures have also been proposed; although a causal relationship between these and disease pathogenesis has yet to be clearly established [10,11]. Genetic vulnerability to PD has been observed in a minority of PD cases (10-15\%) via rare familial mutants, including those in $\alpha$-synuclein that trigger early onset Parkinsonian phenotypes, and other inheritable gene mutations that may contribute to cellular damage, oxidative stress, and inflammation [10,12].

At present, there are no curative treatments for PD, just pharmacotherapy to manage symptoms. The first-line treatment, levodopa, is employed to supplement dopamine levels to mitigate the loss of dopaminergic innervations [13]. Ldopa administration is usually accompanied by a decarboxylase inhibitor such as carbidopa, to limit its peripheral 
metabolism [13-15]. Chronic administration of L-dopa is associated with dyskinesias and reduced drug efficacy, thus making symptom management increasingly difficult with disease progression [13-15]. Similarly, there are no standard neuroprotective medications in PD treatment able to cease disease progression, although monoamine oxidase-B inhibitors (MAO-B) or dopamine receptor agonists may have neuroprotective as well as symptomatic effects [15-17].

\subsection{Cannabis-derived Cannabinoids and Resveratrol as neuroprotective agents}

There has been a recent upsurge in the potential use of dietary polyphenols as neuroprotective agents in PD [18] [Supplementary Figure S1]. Of these, neuro-modulatory cannabis-derived phytocannabinoids (CDCs) and resveratrol (RSV) overlap, such that both can be consumed through recreational use as cannabis and alcoholic drinks including red wine, respectively $[19,20]$.

Cannabis sativa is a natural herbaceous plant historically consumed or smoked for recreational and therapeutic purposes [21,22]. Tetrahydrocannabinol (THC) and cannabidiol (CBD) are major phytocannabinoid constituents of the cannabis plant and are ligands for endogenous cannabinoid receptors [22,23]. Cannabis sativa also contains a plethora of phytochemicals including the minor phytocannabinoids $\beta$-caryophyllene (BCP) and tetrahydrocannabivarin (THCV) [24,25]. BCP is a component of cannabis essential oil and essential oils from cinnamon, black pepper, and oregano [24]. These compounds may display neuroprotective activity via cannabinoid receptor-2 (CB2) agonistic effects, and without exhibiting the psychoactive effects of THC [23-27]. BCP has also been shown to exert anti-inflammatory activity in a model of stroke [26].

RSV is a natural stilbene present in several dietary foodstuffs including berries and grapes, as well as red wine, for which consumption of RSV is associated with a number of purported health benefits $[20,27,28]$. RSV is also a component of the herbaceous root Polygonum Cuspidatum, used in traditional Chinese herbal medicine, with recorded antioxidative and anti-inflammatory effects [29]. The structures of the aforementioned CDCs and RSV are shown in Table 1.

These CDCs and RSV may provide useful neuroprotective agents. Therefore, a systematic review was undertaken to appraise the experimental literature that has considered the potential neuroprotective effects of these CDCs and RSV in pre-clinical animal studies of PD. 
Table 1: Skeletal structures of the neuroprotective agents assessed in this review.

\begin{tabular}{|c|c|}
\hline trans-Resveratrol (RSV) & Cannabidiol (CBD) \\
\hline Tetrahydrocannabinol (THC) & \\
\hline Tetrahydrocannabivarin (THCV) \\
(-)- $\beta$-caryophyllene (BCP)
\end{tabular}

\section{Materials and Methods}

A systematic review of the literature was conducted in accordance with the Preferred Reporting Items for Systematic Reviews and Meta-Analyses (PRISMA) [30].

\subsection{Search Strategy}

An electronic literature search was performed using MEDLINE, EMBASE, PsychINFO, PubMed and Web of Science Core Collection to retrieve pre-clinical experimental studies investigating the neuroprotective effects of these CDCs and RSV in animal models of PD. A combination of Boolean operators (AND/OR) and field tags (multipurpose) were employed for the following major search terms: Parkinson's disease; Parkinson*; cannab*; tetrahydrocannabinol; cannabidiol; $\beta$-caryophyllene; tetrahydrocannabivarin; resveratrol; in vivo; pre-clinical; animal, primate, monkey, rodent, mice, mouse, rat. The full OVID and PubMed search strategy is provided as Supplementary Data S2. The addition of hand-searched studies from references and bibliographies of related publications was performed secondarily. 


\subsection{Eligibility Criteria}

All search results $(n=1034)$ were exported into Endnote for removal of duplicate publications and text analysis with respect to predefined eligibility criteria. Included articles were original, full-text publications investigating the direct neuroprotective effect of CDCs or RSV in PD animal models in vivo, with no restriction on age, dosing, length of study or outcome measures. Studies were excluded if the experiment was performed on non-rodent animals or artificial CDCs or RSV derivatives were used.

\subsection{Data Acquisition and Analysis}

A total of 18 eligible publications were included for review, from which the following variables were extracted to an Excel data spreadsheet: author(s), year of publication, the aim of the study, population, intervention, dosing, length of study, outcome measures and results. For methodological quality assessment, the Systematic Review Centre for Laboratory animal Experimentation (SYRCLE) risk of bias tool was considered (Supplementary Table S1), which has been adapted in accordance with methodology used in animal studies [31].

\section{Results}

The preliminary data search generated 1021 results, reduced to 898 following the removal of duplicates. The addition of 13 hand-searched studies from references and bibliographies of related publications, resulted in a total of 911 papers, which were screened with respect to their titles and abstracts. Of these 911 papers, 836 did not meet the predefined inclusion criteria and were excluded for the following reasons: irrelevant, performed on non-rodent models, in vitro studies, focused on other neurodegenerative diseases, full-text inaccessibility and lack of specificity. Full-text articles were read in full for 75 studies, of which 57 were removed on the grounds of investigating synthetic cannabinoids, cannabinoid receptor agonists or resveratrol-related compounds, and therefore did not meet the eligibility criteria. The remaining 18 studies fulfilled the eligibility criteria and were included in the final analysis of this review (Figure 1). The majority of studies investigated RSV ( $n=12)$ and the remaining studies CDCs (n=6); specifically, tetrahydrocannabinol (THC) $(n=2)$, cannabidiol (CBD) $(n=1)$, tetrahydrocannabivarin $(T H C V)(n=1)$ and $\beta$ caryophyllene (BCP) (n=2). 

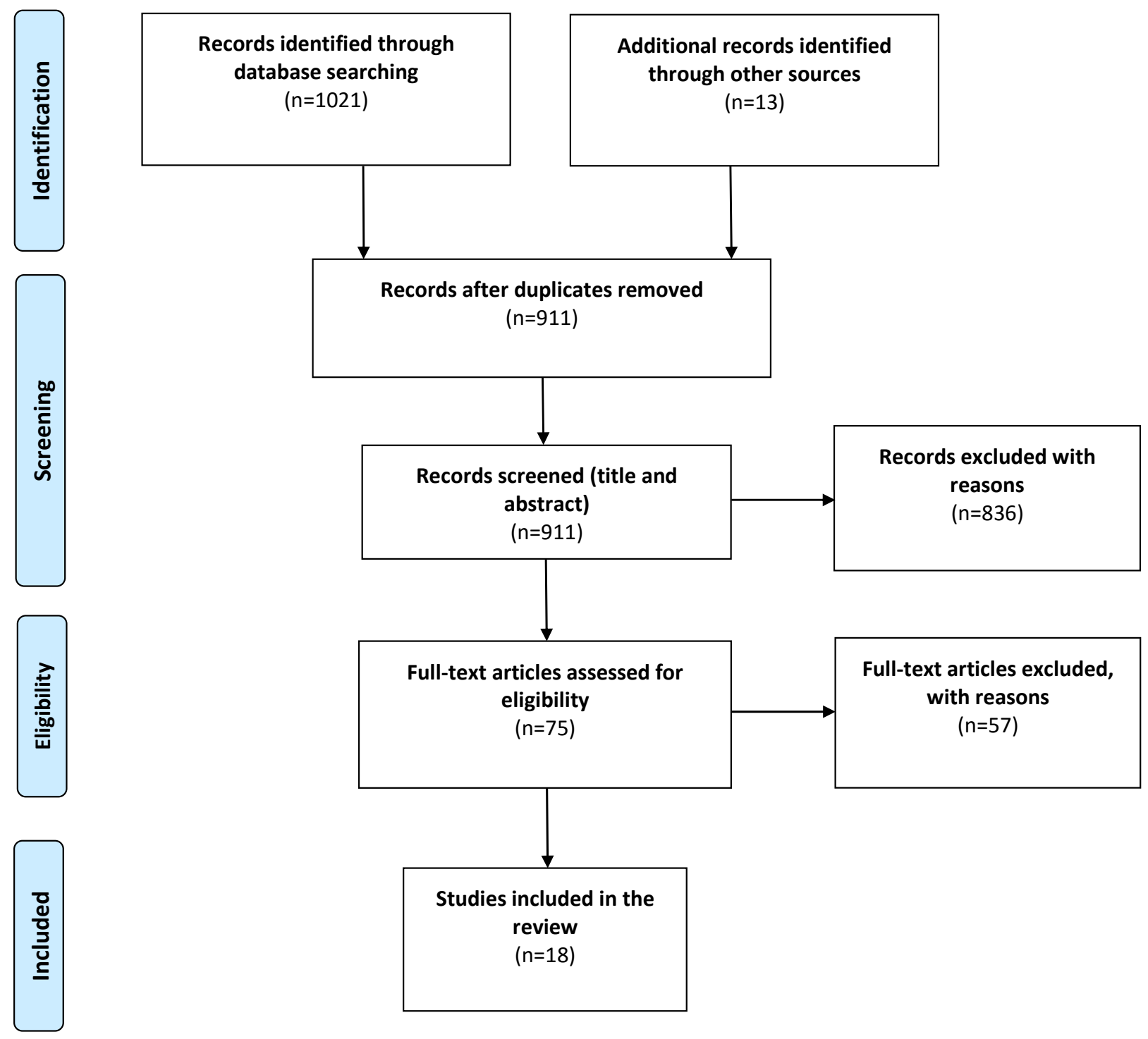

Figure 1. Preferred reporting items for systematic reviews and meta-analyses (PRISMA) flow chart detailing the stages of study retrieval and selection [30].

\subsection{Study Characteristics}

A total of six strains from two different rodent species were assessed: Wistar rats ( $\mathrm{n}=252)$, Sprague Dawley rats $(\mathrm{n}=183)$, C57BL/6 mice $(n=156)$, Balb/C mice $(n=60)$, Swiss Albino mice $(n=42)$ and A53T- $\alpha$ synuclein mice $(n=40)$. Two studies did not report the strain of mice investigated $(n=39)$. An average of 43 rodents was used per study, with a median of 41 and a range of 24-60. All rodents were male. The weight of rats and mice ranged from 180-350g and 20-35g, respectively.

\subsection{Dosing}

A number of different neurotoxic models were used to reproduce a Parkinsonian phenotype, and for which the specific dosing regimens are included in Table 2 [32-49]. 6-Hydroxydopamine (6-OHDA) was administered to rats $(\mathrm{n}=6)$, of which four studies used an average dose of $10 \mu \mathrm{g}$, whilst two studies gave daily injections over 14 days of $8 \mu \mathrm{g}$ and 200 $\mu \mathrm{g}$ [32-37]. Unilateral 6-OHDA lesions were induced via intracerebroventricular injection, striatal injection, medial 
forebrain bundle injection or intraperitoneal injection [32-37]. 1-Methyl-4-phenyl-1,2,3,6-tetrahydropyridine (MPTP) was administered to mice at 30 or $20 \mathrm{mg} / \mathrm{kg}$ intraperitoneally [44-49]. The remaining studies utilised a mean of $2 \mathrm{mg} / \mathrm{kg}$ rotenone $(\mathrm{n}=3), 1 \mathrm{mg} / \mathrm{kg}$ risperidone $(\mathrm{n}=1)$ and $1 \mathrm{mg} / \mathrm{kg}$ of haloperidol $(\mathrm{n}=1)$ to produce neurotoxin-induced PD models [38-42]. Additionally, a single study used $5 \mu \mathrm{g} /$ day of lipopolysaccharide (LPS) over 14 days in a subset of mice [33], and one study did not utilise a neurotoxin, but instead assessed the effects of RSV on transgenic A53T $\alpha$-synuclein mice that naturally developed $\alpha$-synuclein aggregates at 9-16 months of age [43].

Twelve studies investigated the neuroprotective effect of RSV using a dosing range of 10-100 mg/kg body weight (bw) per day; and a duration of dosing that varied from 1 to 10 weeks [34-37,40,42-48]. The most common route of administration was per os (p.o.), including oral and intragastric gavage. Two studies used intraperitoneal and intravenous routes, with RSV dissolved in $20 \%$ ethanol [35,48]. Six of 18 studies investigated the neuroprotective effects of four different CDCs [32,33,38,39,41,49]. Rodents in two studies were given THC at a dose of either 3, 10 or $20 \mathrm{mg} / \mathrm{kg}$ daily for 14-18 days [32,38]. THCV, CBD and BCP were used in five studies with doses of 0.5-3 mg/kg and 10-50 mg/kg bw $[32,33,39,41,49]$.

Table 2. Study Characterisitcs and Outcome Summary

\begin{tabular}{|c|c|c|c|c|}
\hline $\begin{array}{l}\text { Author and } \\
\text { Year }\end{array}$ & $\begin{array}{l}\text { Species and strain, } \\
\text { study population }\end{array}$ & $\begin{array}{c}\text { Neurotoxin model, dose, route } \\
\text { of administration, length of } \\
\text { dosing }\end{array}$ & $\begin{array}{l}\text { Main intervention groups: } \\
\text { compound, dose, frequency }\end{array}$ & $\begin{array}{c}\text { Outcomes in main interventional } \\
\text { groups }\end{array}$ \\
\hline $\begin{array}{l}\text { Ojha et al. (2016) } \\
\text { [39] }\end{array}$ & $\begin{array}{l}\text { Wistar rats. Four } \\
\text { Groups }(\mathrm{n}=8)\end{array}$ & $\begin{array}{l}\text { Rotenone induced }(2.5 \mathrm{mg} / \mathrm{kg} \\
\text { bw per day, i.p.); } 28 \text { days }\end{array}$ & $\begin{array}{c}\mathrm{BCP}(50 \mathrm{mg} / \mathrm{kg} \text { bw per day } \\
\text { dissolved in olive oil i.p.); } 28 \text { days }\end{array}$ & $\begin{array}{c}\downarrow \text { DAN loss } \\
\downarrow \text { OS markers } \\
\downarrow \text { Inflammatory markers } \\
\end{array}$ \\
\hline $\begin{array}{l}\text { Viveros-Paredes } \\
\text { et al. (2017) [49] }\end{array}$ & $\begin{array}{l}\text { C57BL/6J mice. Six } \\
\text { groups }(n=6)\end{array}$ & $\begin{array}{l}\text { MPTP induced }(30 \mathrm{mg} / \mathrm{kg} \text { bw } \\
\text { per day, i.p.); } 5 \text { days }\end{array}$ & $\begin{array}{c}\text { BCP (10 mg/kg bw per day i.p. }) ; 5 \\
\text { days. } \\
\text { BCP (10 mg/kg bw per day o.g. }) ; 5 \\
\text { days }\end{array}$ & $\begin{array}{c}\uparrow \text { TH-positive neurones } \\
\downarrow \text { pole test time (s), } \uparrow \text { stride length in } \\
\text { gait test, } \downarrow \text { time in beam test (s) } \\
\downarrow \text { inflammatory markers }\end{array}$ \\
\hline $\begin{array}{l}\text { Peres et al. (2016) } \\
\qquad[41]\end{array}$ & $\begin{array}{l}\text { Wistar rats. Four } \\
\text { Groups }(\mathrm{n}=10)\end{array}$ & $\begin{array}{l}\text { Reserpine induced }(1 \mathrm{mg} / \mathrm{kg} \\
\text { bw per day, s.c.); } 2 \text { days }\end{array}$ & $\begin{array}{l}\mathrm{CBD}(0.5 \mathrm{mg} / \mathrm{kg} \text { and } 5 \mathrm{mg} / \mathrm{kg} \text { bw } \\
\text { per day dissolved in saline, i.p...); } 3 \\
\text { days }\end{array}$ & $\downarrow$ catalepsy \\
\hline $\begin{array}{l}\text { Lastres-Becker et } \\
\text { al. (2005) [32] }\end{array}$ & $\begin{array}{l}\text { SD rats. Four groups } \\
\qquad(\mathrm{n}=7+)\end{array}$ & $\begin{array}{l}\text { 6-OHDA induced }(8 \mu \mathrm{g} \\
\text { m.f.b.i. }) ; 14 \text { days }\end{array}$ & $\begin{array}{c}\text { THC ( } 3 \mathrm{mg} / \mathrm{kg} \text { bw per day, } \\
\text { dissolved in saline i.p.); } 14 \text { days. } \\
\text { CBD (3 mg/kg bw per day dissolved } \\
\text { in saline i.p.); } 14 \text { days }\end{array}$ & $\uparrow \mathrm{TH}$ mRNA \\
\hline $\begin{array}{l}\text { Abdel-Salam et } \\
\text { al. (2012) [38] }\end{array}$ & $\begin{array}{l}\text { SA mice. Seven } \\
\text { groups }(n=6)\end{array}$ & $\begin{array}{l}\text { Haloperidol induced }(1 \mathrm{mg} / \mathrm{kg} \\
\text { bw per day, i.p.); } 18 \text { days }\end{array}$ & $\begin{array}{c}\text { Cannabis extract THC }(10 \mathrm{mg} / \mathrm{kg} \\
\text { and } 20 \mathrm{mg} / \mathrm{kg} \text { bw per day, dissolved } \\
\text { in ethanol s.c. }) ; 18 \text { days }\end{array}$ & $\begin{array}{c}\downarrow \text { catalepsy } \\
\downarrow \text { OS markers }\end{array}$ \\
\hline $\begin{array}{l}\text { Garcia et al. } \\
\text { (2011) [33] }\end{array}$ & $\begin{array}{c}\text { SD rats, CB2 -/- mice, } \\
\text { wild-type littermates. } \\
\text { Twelve groups } \\
(\mathrm{n}=5-6)\end{array}$ & $\begin{array}{l}\text { 6-OHDA induced rats }(200 \mu \mathrm{g} \\
\text { per day, i.c.v.); } 14 \text { days. } \\
\text { LPS induced mice ( } 5 \mu \mathrm{g} \text { per } \\
\text { day, i.c.v.); } 14 \text { days }\end{array}$ & $\begin{array}{c}\text { THCV (2 mg/kg bw dissolved in } \\
\text { saline i.p., single dose } 14 \text { days post- } \\
\text { lesion.) } \\
\text { THCV (2 mg/kg bw per day } \\
\text { dissolved in saline i.p.); } 14 \text { days }\end{array}$ & $\begin{array}{c}\uparrow \text { activity in CAA test } \\
\downarrow \text { DAN loss, } \uparrow \text { TH-positive neurons }\end{array}$ \\
\hline $\begin{array}{l}\text { Zhang et al. } \\
\text { (2018) [43] }\end{array}$ & $\begin{array}{l}\text { A53T } \alpha \text {-synuclein } \\
\text { mice, wild-type } \\
\text { littermates. Five } \\
\text { groups }(\mathrm{n}=8)\end{array}$ & $\begin{array}{l}\text { A53T } \alpha \text {-synuclein mouse } \\
\text { model. }\end{array}$ & $\begin{array}{l}\mathrm{RSV}(10 \mathrm{mg} / \mathrm{kg} \text { and } 50 \mathrm{mg} / \mathrm{kg} \text { bw } \\
\text { per day, o.g.; } 35 \text { days })\end{array}$ & $\begin{array}{c}\downarrow \alpha \text {-synuclein } \\
\downarrow \text { activity in open field test, } \\
\uparrow \text { cognitive performance, } \downarrow \text { hindlimb } \\
\text { clasping, } \downarrow \text { time pole test (s) } \\
\downarrow \text { OS markers } \\
\downarrow \text { inflammatory markers }\end{array}$ \\
\hline $\begin{array}{l}\text { Anandhan et al. } \\
\text { (2010) [46] }\end{array}$ & $\begin{array}{l}\text { Albino C57BL/6 mice. } \\
\text { Four groups }(n=12)\end{array}$ & $\begin{array}{l}\text { MPTP induced }(30 \mathrm{mg} / \mathrm{kg} \text { bw } \\
\text { per day i.p.); } 4 \text { days }\end{array}$ & $\begin{array}{c}\mathrm{RSV}(50 \mathrm{mg} / \mathrm{kg} \text { bw per day, p.o. }) ; 7 \\
\text { days }\end{array}$ & $\begin{array}{c}\uparrow \text { DA } \\
\uparrow \text { activity in open field test, } \\
\uparrow \text { retention time on the rotarod, } \\
\downarrow \text { time in beam test } \\
\downarrow \text { OS markers }\end{array}$ \\
\hline
\end{tabular}




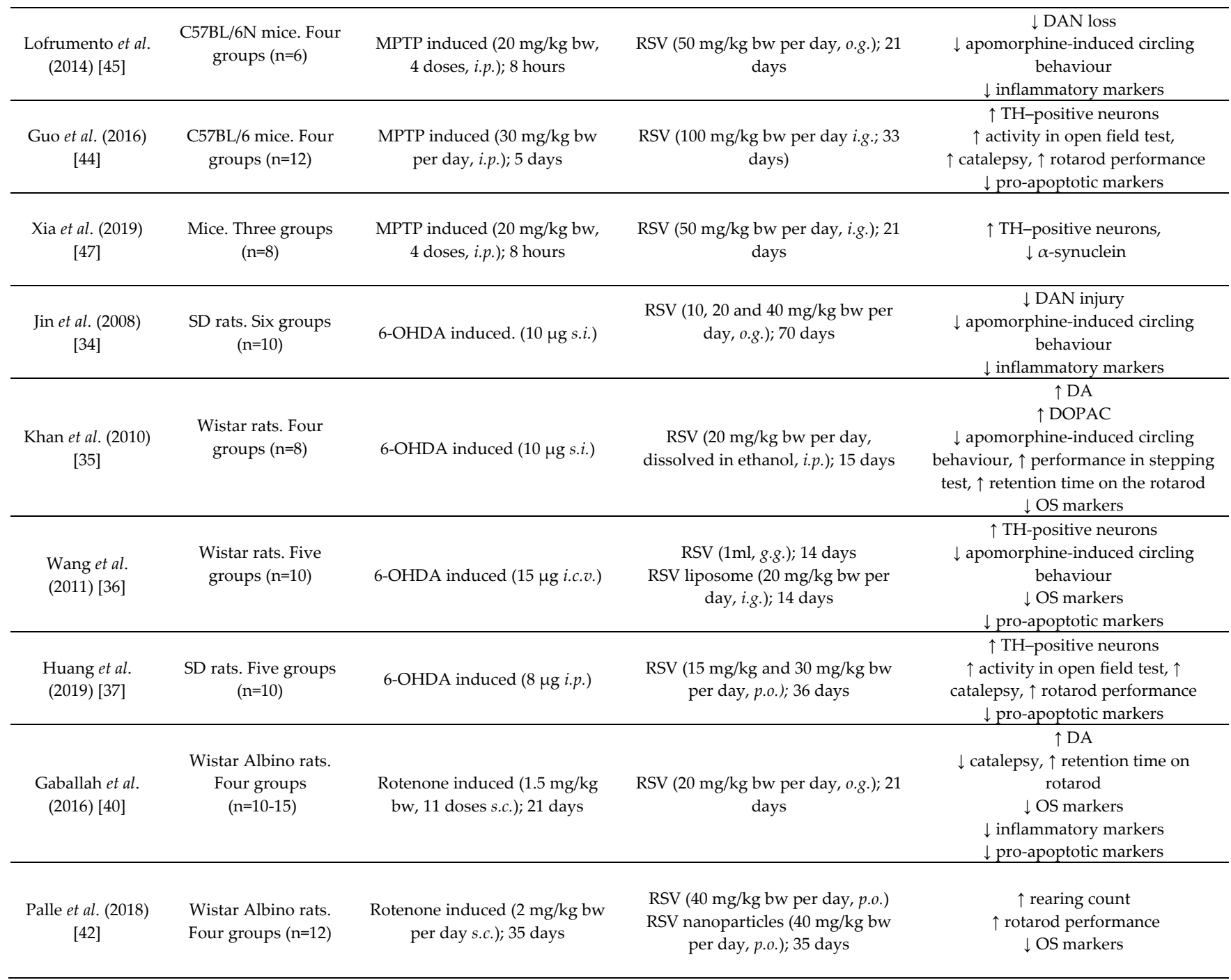

Abbreviations: $\mathrm{BCP}, \beta$-caryophyllene; bw, bodyweight; $\mathrm{CBD}$, cannabidiol; $\mathrm{CAA}$, computer-aided actimeter; DA, dopamine; DAN, dopaminergic neurons; DOPAC, 3,4-Dihydroxyphenylacetic acid; g.g., gastric gavage; 6-OHDA, 6-Hydroxydopamine; i.c.v., intracerebroventricular cannulation; i.g., intragastric gavage; i.p., intraperitoneal; i.v., intravenous; LPS, lipopolysaccharide; m.f.b.i, median foramen bundle injection; MPTP, 1-methyl-4-phenyl-1,2,3,6tetrahydropyridine; o.g., oral gavage; OS, oxidative stress; p.o., per os; RSV, resveratrol; SA, Swiss Albino; s.c., subcutaneous; SD, Sprague Dawley; s.i., striatal injection; TH, tyrosine hydroxylase; THC, $\Delta^{9}$-tetrahydrocannabinol; THCV, tetrahydrocannabivarin.

\subsection{Behavioural Outcomes}

There were 14 studies that incorporated an array of behavioural outcome measures to observe cognitive and motor changes in rodent PD models and assessed whether these impairments were mitigated by the administration of CDCs or RSV. The results of these studies are listed in Table 3.

\subsubsection{Open Field Testing and Movement}

A single study evaluated the neuroprotective effect of CBD in a risperidone-induced PD rat model using an open field circular arena and concluded that the locomotor activity of the risperidone group was significantly lower than the control group [41]. CBD treatment ameliorated risperidone-induced memory deficits but not locomotor activity, although oral movements as vacuous chewing were also reduced after treatment with CBD [41]. 
Motor activity was also examined using a computer-aided actimeter (CAA) and reported a significant increase in distance travelled and mean velovity in THCV-treated rodents when compared to the PD model [33].

PD model rodents displayed reduced velocity, rearing and distance travelled and these impairments were significantly improved by RSV treatment [37,42,44,46]. By contrast, a single study reported increased velocity in a PD model (A53T $\alpha$-synuclein mice), but that was returned to control levels after treatment with RSV [43].

Rotational (circling) behaviour was examined in three studies and demonstrated the benefit of RSV treatment to reduce apomorphine-induced circling behaviour [34-36].

\subsubsection{Rotarod and Grasp Strength}

A rotarod test was used to assess grip strength and balance. Measurements were based on the time rodents remained on a rotating metal rod before falling off. Across six studies that used this method, all investigated the effects of RSV, but with slightly different experimental methods. The size of the rods ranged from $0.75-6 \mathrm{~cm}$ in diameter and maximum rotational speed varied from 12-20 rotations per minute. All studies showed reduced retention time on the rotarod in PD model groups relative to control groups [35,37,40,42,46,48]. One study also assessed grasp strength (g), measured by having rodents hold onto a horizontal bar over six trials. In comparison with the control group, the PD model group displayed increased grasp strength, indicating muscle rigidity, and this grasp strength was reduced by RSV administration [48].

\subsubsection{Pole and Beam test}

A pole test was used to assess bradykinesia and was performed by placing the rodent at the top of a pole with its head facing upwards. The time that was taken for a rodent to turn around and descend the pole was recorded. Of the three studies that used this measure, the height of the pole varied from 50-55 cm. An average of at least 3 trials was recorded per study. The beam test is similar, with rodents placed at one end of a narrow beam, and the time taken to reach the other end measured. Rodents within the PD model groups spent a significantly increased time in the beam and pole tests compared to controls, whereas rodents that received BCP both orally and i.p., or RSV, displayed significantly decreased beam and pole test times $[43,44,46,49]$.

\subsubsection{Gait Assessment and Stepping Test}

Gait assessment was used to monitor a change in stride length by measuring the distances between forepaw prints in rodents. A shortened stride length is observed for rodent models of PD [50]. Provision of oral or i.p. BCP or administered RSV countered this reduced stride length [44,49]. A stepping test was also performed in a single study, and the number of adjusting steps taken when forced to walk on one forepaw was recorded. There was a reduction of adjustment steps in the PD model group, which was significantly rectified by RSV administration [35].

\subsubsection{Catalepsy}

Catalepsy, a decrease in movement and inability to correct abnormal posture, was assessed by both the bar test and the grid test across four studies. The bar test involved placing a rodent's hindlimbs on a bench and their forepaws on an elevated horizontal bar, and quantification of the time that they remain in this position. Catalepsy was attenuated in CBD and THC administered groups, resulting in a significantly decreased time spent in the bar test [38,41]. Two studies 
employed a grid test in which rodents were hung from a vertical grid approximately $0.5 \mathrm{~m}$ high. One study measured the time taken for the rodent to initiate corrective movement [40], whilst the other measured the time taken to fall from the grid [37]. Both studies showed significantly increased catalepsy in PD model groups, and this was significantly rectified after receiving RSV [37,40].

\subsubsection{Apomorphine-induced circling behaviour}

Apomorphine-induced circling behaviour was assessed in three studies. Apomorphine, a non-selective DA receptor agonist influences rotational behaviour in rodents [51]. Apomorphine was administered subcutaneously to rats and the net number of contralateral rotations was measured over a time course. All studies demonstrated increased rotational behaviour in the PD model group of rats, and that RSV significantly decreased the number of rotations [34-36].

Table 3. Summary of behavioural outcomes in PD model groups and interventions.

\begin{tabular}{|c|c|c|c|c|c|}
\hline Author \& Year & Intervention & $\begin{array}{c}\text { Behavioural Outcomes in PD Model } \\
\text { Group (vs Controls) }\end{array}$ & $\begin{array}{c}\text { Level of } \\
\text { Significance }\end{array}$ & $\begin{array}{c}\text { Behavioural Changes in Main } \\
\text { Intervention Group (vs PD Model } \\
\text { Group) }\end{array}$ & $\begin{array}{c}\text { Level of } \\
\text { Significance }\end{array}$ \\
\hline \multirow{3}{*}{$\begin{array}{l}\text { Viveros-Paredes et al. } \\
\qquad \text { (2017) [49] }\end{array}$} & \multirow{3}{*}{ ВСР } & $\uparrow$ pole test time (s) & $(p<0.001)$ & $\downarrow$ pole test time (s) & $(p<0.01)$ \\
\hline & & $\downarrow$ stride length in gait test & $(p<0.01)$ & $\uparrow$ stride length in gait test & $(p<0.05)$ \\
\hline & & $\uparrow$ time in beam test (s) & $(p<0.01)$ & $\downarrow$ time in beam test (s) & $(p<0.01)$ \\
\hline \multirow{3}{*}{ Peres et al. (2016) [41] } & \multirow{3}{*}{ CBD } & $\downarrow$ activity in open field test & \multirow{3}{*}{$(p<0.05)$} & $\begin{array}{c}\uparrow \text { memory deficit but not locomotor } \\
\text { activity in open field test }\end{array}$ & \multirow{3}{*}{$(p<0.05)$} \\
\hline & & $\uparrow$ catalepsy & & $\downarrow$ catalepsy & \\
\hline & & $\uparrow$ vacuous chewing & & $\downarrow$ vacuous chewing & \\
\hline $\begin{array}{l}\text { Abdel-Salam et al. } \\
\qquad \text { (2012) [38] }\end{array}$ & THC & $\uparrow$ catalepsy & $(p<0.05)$ & $\downarrow$ catalepsy & $(p<0.05)$ \\
\hline $\begin{array}{c}\text { Garcia et al. (2011) } \\
\text { [33] }\end{array}$ & THCV & $\downarrow$ activity in CAA test & $(p<0.05)$ & $\uparrow$ activity in CAA test & $(p<0.05)$ \\
\hline Jin et al. (2008) [34] & RSV & $\begin{array}{c}\uparrow \text { apomorphine-induced circling } \\
\text { behaviour } \\
\end{array}$ & ND & $\begin{array}{c}\downarrow \text { apomorphine-induced circling } \\
\text { behaviour }\end{array}$ & $(p<0.01)$ \\
\hline \multirow{3}{*}{ Lu et al. (2008) [48] } & \multirow{3}{*}{ RSV } & $\downarrow$ retention time on rotarod & & $\uparrow$ retention time on rotarod & \multirow{3}{*}{$(p<0.05)$} \\
\hline & & & $(p<0.05)$ & & \\
\hline & & $\uparrow$ grasp strength & & $\downarrow$ grasp strength & \\
\hline \multirow{3}{*}{$\begin{array}{l}\text { Anandhan et al. } \\
\text { (2010) [46] }\end{array}$} & \multirow{3}{*}{ RSV } & $\downarrow$ activity in open field test & & $\uparrow$ activity in open field test & \multirow{3}{*}{$(p<0.05)$} \\
\hline & & $\uparrow$ time in beam test & $(p<0.05)$ & $\downarrow$ time in beam test & \\
\hline & & $\downarrow$ retention time on rotarod & & $\uparrow$ retention time on the rotarod & \\
\hline \multirow{3}{*}{ Khan et al. (2010) [35] } & \multirow{3}{*}{ RSV } & $\begin{array}{c}\uparrow \text { apomorphine-induced circling } \\
\text { behaviour }\end{array}$ & $(p<0.01)$ & $\begin{array}{c}\downarrow \text { apomorphine-induced circling } \\
\text { behaviour }\end{array}$ & $(p<0.05)$ \\
\hline & & $\downarrow$ retention time on rotarod & $(p<0.001)$ & $\uparrow$ retention time on the rotarod & $(p<0.05)$ \\
\hline & & $\downarrow$ performance in stepping test & $(p<0.01)$ & $\uparrow$ performance in stepping test & $(p<0.05)$ \\
\hline
\end{tabular}




\begin{tabular}{|c|c|c|c|c|c|}
\hline $\begin{array}{c}\text { Wang et al. (2011) } \\
\text { [36] }\end{array}$ & RSV & $\begin{array}{c}\uparrow \text { apomorphine-induced circling } \\
\text { behaviour }\end{array}$ & $(p<0.01)$ & $\begin{array}{c}\downarrow \text { apomorphine-induced circling } \\
\text { behaviour }\end{array}$ & $(p<0.01)$ \\
\hline \multirow{3}{*}{$\begin{array}{c}\text { Gaballah et al. (2016) } \\
{[40]}\end{array}$} & \multirow{3}{*}{ RSV } & $\uparrow$ catalepsy & & $\downarrow$ catalepsy & \multirow{3}{*}{$(p<0.05)$} \\
\hline & & & $(p<0.05)$ & & \\
\hline & & $\downarrow$ retention time on rotarod & & $\uparrow$ retention time on rotarod & \\
\hline \multirow{3}{*}{ Guo et al. (2016) [44] } & \multirow{3}{*}{ RSV } & $\downarrow$ activity in open field test & $(p<0.001)$ & $\uparrow$ activity in open field test & $(p<0.001)$ \\
\hline & & $\downarrow$ stride length in gait test & $(p<0.001)$ & $\uparrow$ stride length in gait test & $(p<0.001)$ \\
\hline & & $\uparrow$ time pole test (s) & $(p<0.01)$ & $\downarrow$ time pole test (s) & $(p<0.01)$ \\
\hline \multirow{3}{*}{ Palle et al. (2018) [42] } & \multirow{3}{*}{ RSV } & $\downarrow$ rearing count & \multirow{2}{*}{\multicolumn{2}{|c|}{$\uparrow$ rearing count }} & \\
\hline & & & & & $(p<0.05)$ \\
\hline & & $\downarrow$ retention time on rotarod & & $\uparrow$ retention time on rotarod & \\
\hline \multirow{4}{*}{$\begin{array}{c}\text { Zhang et al. (2018) } \\
\text { [43] }\end{array}$} & \multirow{4}{*}{ RSV } & $\uparrow$ activity in open field test & $(p<0.05)$ & $\downarrow$ activity in open field test & $(p<0.05)$ \\
\hline & & $\uparrow$ time pole test (s) & $(p<0.001)$ & $\downarrow$ time pole test (s) & $(p<0.01)$ \\
\hline & & $\uparrow$ hindlimb clasping & $(p<0.001)$ & $\downarrow$ hindlimb clasping & $(p<0.05)$ \\
\hline & & $\downarrow$ cognitive performance & $(p<0.05)$ & $\uparrow$ cognitive performance & $(p<0.05)$ \\
\hline \multirow{3}{*}{$\begin{array}{c}\text { Huang et al. (2019) } \\
\qquad \text { [37] }\end{array}$} & \multirow{3}{*}{ RSV } & $\downarrow$ retention time on rotarod & $(p<0.05)$ & $\uparrow$ rotarod performance & $(p<0.05)$ \\
\hline & & $\downarrow$ activity in open field test & $(p<0.01)$ & $\uparrow$ activity in open field test & $(p<0.01)$ \\
\hline & & $\uparrow$ catalepsy & $(p<0.05)$ & $\uparrow$ catalepsy & $(p<0.05)$ \\
\hline
\end{tabular}

Abbreviations: BCP, $\beta$-caryophyllene; CAA, computer-aided actimeter; ND, Not determined; RSV, resveratrol; THC, $\Delta^{9}$-tetrahydrocannabinol.

\subsection{Biochemical and Immunohistochemical Outcomes}

Thirteen studies assessed the neuroprotective effect of CDCs or RSV via an assessment of the levels of dopaminergic neurons and dopamine in the striatum of rodents, and related metabolites such as 3,4-dihydroxyphenylacetic acid (DOPAC) and homovanillic acid (HVA) [32-34,36,37,39,40,43-47,49]. The results of these studies have been detailed in Table 4 . The striatal concentration of tyrosine-hydroxylase (TH) markers were quantified in nine studies [32,33,36,37,43$45,47,49]$. One study showed a significant 5-fold decrease in striatal dopamine levels in a 6-OHDA-induced PD model, that was partially restored by THCV administration, although this did not reach significance [33]. The same study showed a significant decrease in SNpc dopaminergic neurons in LPS-lesioned mice, which was significantly restored via administration of THCV or cannabidiol (CBD)-derived drug (HU-308) in interventional groups [33]. There was a substantial decrease in striatal dopamine and DOPAC in 6-OHDA treated mice, in addition to decreased THimmunostaining and TH mRNA when compared to control groups, and these decreases were significantly improved by administration of THC in interventional groups [32]. TH immunoreactivity levels also showed a significant decrease in two studies using neurotoxin-PD-induced Wistar rats and C57BL/6J mice, which was significantly restored by BCP administration $[39,49]$. For markers of dopamine loss (DA and DAN) or injury that had declined in PD model groups, all could be significantly restored in interventional groups treated with RSV [34,39,40,45,46]. 
Table 4. Summary of biochemical and immunohistochemical analyses in PD model groups and interventions.

\begin{tabular}{|c|c|c|c|c|c|}
\hline Author \& Year & Intervention & $\begin{array}{c}\text { Changes in Dopamine and } \alpha \text { - } \\
\text { synuclein in PD Model Groups (vs } \\
\text { Control) }\end{array}$ & $\begin{array}{c}\text { Level of } \\
\text { Significance }\end{array}$ & $\begin{array}{c}\text { Changes in Dopamine and } \alpha \text { - } \\
\text { synuclein in Main Interventional } \\
\text { Groups (vs PD Model) }\end{array}$ & $\begin{array}{c}\text { Level of } \\
\text { Significance }\end{array}$ \\
\hline Ojha et al. (2016) [39] & $\mathrm{BCP}$ & $\uparrow \mathrm{DAN}$ loss & $(p<0.05)$ & $\downarrow$ DAN loss & $(p<0.05)$ \\
\hline $\begin{array}{c}\text { Viveros-Paredes et al. } \\
\text { (2017) [49] }\end{array}$ & ВСР & $\downarrow \mathrm{TH}$-positive neurons & $(p<0.001)$ & $\uparrow \mathrm{TH}$-positive neurons & $(p<0.05)$ \\
\hline $\begin{array}{c}\text { Lastres-Becker et al. (2005) } \\
\text { [32] }\end{array}$ & THC or CBD & $\begin{array}{l}\downarrow \text { TH activity } \\
\downarrow \text { TH mRNA } \\
\end{array}$ & $\begin{array}{l}(p<0.05) \\
(p<0.01)\end{array}$ & $\begin{array}{l}\uparrow \mathrm{TH} \text { activity } \\
\uparrow \mathrm{TH} \text { mRNA } \\
\end{array}$ & $\begin{array}{l}(p<0.05) \\
(p<0.05)\end{array}$ \\
\hline Garcia et al. (2011) [33] & THCV & $\begin{array}{c}\uparrow \text { DAN loss } \\
\downarrow \text { TH-positive neurons } \\
\end{array}$ & $\begin{array}{l}(p<0.05) \\
(p<0.005)\end{array}$ & $\begin{array}{c}\downarrow \text { DAN loss } \\
\uparrow \mathrm{TH}-\text { positive neurons } \\
\end{array}$ & $\begin{array}{l}(p>0.05) \\
(p<0.05) \\
\end{array}$ \\
\hline Jin et al. (2008) [34] & RSV & $\uparrow \mathrm{DAN}$ injury & - & $\downarrow$ DAN injury & - \\
\hline $\begin{array}{c}\text { Anandhan et al. (2010) } \\
\qquad[46]\end{array}$ & RSV & $\begin{array}{c}\downarrow \text { DA } \\
\downarrow \text { DOPAC } \\
\downarrow \text { HVA }\end{array}$ & $(p<0.05)$ & $\begin{array}{c}\uparrow \mathrm{DA} \\
\uparrow \mathrm{DOPAC} \\
\uparrow \mathrm{HVA}\end{array}$ & $(p<0.05)$ \\
\hline Wang et al. (2011) [36] & RSV & $\downarrow$ TH-positive cells & $(p<0.05)$ & $\uparrow$ TH-positive cells & $(p<0.01)$ \\
\hline $\begin{array}{l}\text { Lofrumento et al. (2014) } \\
\text { [45] }\end{array}$ & RSV & $\downarrow$ TH immunoreactivity & $(p<0.01)$ & $\uparrow \mathrm{TH}$ immunoreactivity & $(p<0.01)$ \\
\hline Guo et al. (2016) [44] & RSV & $\downarrow$ TH-positive neurons & $(p<0.001)$ & $\uparrow \mathrm{TH}$-positive neurons & $(p<0.01)$ \\
\hline Gaballah et al. (2016) [40] & RSV & $\downarrow D A$ & $(p<0.05)$ & $\uparrow \mathrm{DA}$ & $(p<0.05)$ \\
\hline Zhang et al. (2018) [43] & RSV & $\begin{array}{c}\uparrow \alpha \text {-synuclein } \\
\uparrow \mathrm{A}-11 \text { positive oligomers } \\
\uparrow \mathrm{W} 20 \text { positive oligomers } \\
\downarrow \mathrm{TH} \text {-positive neurons }\end{array}$ & $\begin{array}{l}(p<0.001) \\
(p<0.001) \\
(p<0.001) \\
(p<0.01)\end{array}$ & $\begin{array}{c}\downarrow \alpha \text {-synuclein } \\
\downarrow \text { A-11 positive oligomers } \\
\downarrow \text { W20 positive oligomers } \\
\uparrow \mathrm{TH} \text {-positive neurons }\end{array}$ & $\begin{array}{c}(p<0.001) \\
(p<0.05) \\
(p<0.05) \\
\quad-\end{array}$ \\
\hline Huang et al. (2019) [37] & RSV & $\downarrow$ TH-positive neurons & $(p<0.05)$ & $\uparrow \mathrm{TH}-$ positive neurons & $(p<0.05)$ \\
\hline Xia et al. (2019) [47] & RSV & $\begin{array}{c}\downarrow \text { TH-positive neurons } \\
\uparrow \alpha \text {-synuclein }\end{array}$ & $(p<0.05)$ & $\begin{array}{c}\uparrow \mathrm{TH} \text {-positive neurons } \\
\downarrow \alpha \text {-synuclein }\end{array}$ & $(p<0.05)$ \\
\hline
\end{tabular}

Abbreviations: BCP, $\beta$-caryophyllene; DOPAC, 3,4-dihydroxyphenylacetic acid; DA, dopamine; DAN, dopaminergic neurons; HVA, homovanillic acid; RSV, resveratrol; TH, tyrosine-hydroxylase; THC, $\Delta^{9}$-tetrahydrocannabinol; THCV, tetrahydrocannabivarin.

\subsection{The effectiveness of CDCs or resveratrol to combat oxidative stress}

Nine studies investigated the effects of CDC's and RSV on oxidative stress in rodent brain tissue [35,36,38-40,42,43,46,48]. The results of these studies are shown in Table 5. Protein carbonyl content (PCC), nitric oxide (NO) levels, malondialdehyde (MDA) levels and thiobarbituric acid reactive substances (TBARS) (by-products of lipid peroxidation reactions), were investigated in studies researching the effects of THC, BCP and RSV. Levels of PCC, NO, MDA and TBARS were increased in PD model groups relative to controls, and these were significantly attenuated by treatment with THC, BCP or RSV [35,38-40,42,43,46]. Increased ROS and dihydroxybenzoic acid (DHBA) levels are indicative of 
elevated free radical levels, and these were increased in the PD model groups for three studies investigating the effects of RSV. These increases were significantly attenuated by RSV administration $[36,43,48]$.

Endogenous anti-oxidative agents including reduced glutathione (GSH), and the enzymes, superoxide dismutase (SOD), catalase (CAT), glutathione reductase (GR), glutathione peroxidase (GPx), xanthine oxidase (XO), as well as the citric acid cycle enzymes aconitase, citrate synthase (CS), and succinate dehydrogenase (SDH) were investigated as markers of oxidative stress across seven studies that investigated the effects of BCP, THC and RSV [35,38-40,42,43,46]. These studies showed decreased antioxidant capacity in PD model groups, which could be significantly mitigated by BCP, TCH or RSV administration [35,38-40,42,43,46], except for the study of Anandhan et al. (2010) [46] that reported elevated SOD and CAT activities in their PD model. Total antioxidant capacity (T-AOC) was also increased in response to RSV treatment in the intervention group [36]. One study also monitored mitochondrial complex-I (MC-1) activity, which was decreased in the PD model group but significantly increased by RSV treatment [42]. Antioxidant defence was driven by increased Nrf-2 DNA binding activity in the RSV treated group relative to the PD model group [40].

Table 5. Summary of biochemical and immunohistochemical analysis for oxidative stress markers inPD model groups and interventions. 


\begin{tabular}{|c|c|c|c|c|c|}
\hline Author \& Year & Intervention & $\begin{array}{l}\text { Changes in Oxidative Stress in } \\
\text { PD Model Group (vs Control) }\end{array}$ & $\begin{array}{c}\text { Level of } \\
\text { Significance }\end{array}$ & $\begin{array}{l}\text { Changes in Oxidative Stress } \\
\text { Markers in Main Intervention } \\
\text { Group (vs PD Model Group) }\end{array}$ & $\begin{array}{c}\text { Level of } \\
\text { Significance }\end{array}$ \\
\hline Ojha et al. (2016) [39] & ВСР & $\begin{array}{c}\downarrow \mathrm{GSH} \\
\uparrow \mathrm{MDA} \\
\downarrow \mathrm{SOD} \text { and CAT }\end{array}$ & $(p<0.01)$ & $\begin{array}{c}\uparrow \mathrm{GSH} \\
\downarrow \mathrm{MDA} \\
\uparrow S \mathrm{SO} \text { and CAT }\end{array}$ & $(p<0.05)$ \\
\hline $\begin{array}{l}\text { Abdel-Salam et al. (2012) } \\
\qquad[38]\end{array}$ & THC & $\begin{array}{c}\uparrow \mathrm{MDA} \\
\uparrow \mathrm{NO} \\
\downarrow \mathrm{GSH} \\
\end{array}$ & $(p<0.05)$ & $\begin{array}{c}\downarrow \mathrm{MDA} \\
\downarrow \mathrm{NO} \\
\uparrow \mathrm{GSH} \\
\end{array}$ & $(p<0.05)$ \\
\hline Lu et al. (2008) [48] & RSV & $\uparrow \mathrm{DHBA}$ & $(p<0.05)$ & $\downarrow$ DHBA & $(p<0.05)$ \\
\hline Anandhan et al. (2010) [46] & RSV & $\begin{array}{c}\downarrow \text { GSH } \\
\uparrow S O D \text { and CAT } \\
\uparrow \text { TBARS } \\
\downarrow \text { GPx }\end{array}$ & $(p<0.05)$ & $\begin{array}{c}\uparrow \mathrm{GSH} \\
\downarrow \text { SOD and CAT } \\
\downarrow \text { TBARS } \\
\uparrow \mathrm{GPx}\end{array}$ & $(p<0.05)$ \\
\hline Khan et al. (2010) [35] & RSV & $\begin{array}{c}\uparrow \text { TBARS } \\
\uparrow \mathrm{PCC} \\
\downarrow \mathrm{GSH} \\
\downarrow \mathrm{GPx} \\
\downarrow \mathrm{GR} \\
\downarrow \mathrm{SOD} \\
\downarrow \mathrm{CAT}\end{array}$ & $\begin{array}{l}(p<0.001) \\
(p<0.01) \\
(p<0.01) \\
(p<0.01) \\
(p<0.05) \\
(p<0.05) \\
(p<0.01)\end{array}$ & $\begin{array}{c}\downarrow \text { TBARS } \\
\downarrow \text { PCC } \\
\uparrow \mathrm{GSH} \\
\uparrow \mathrm{GPx} \\
\uparrow \mathrm{GR} \\
\uparrow \mathrm{SOD} \\
\uparrow \mathrm{CAT}\end{array}$ & $\begin{array}{l}(p<0.01) \\
(p<0.05) \\
(p<0.05) \\
(p<0.05) \\
(p<0.05) \\
(p<0.01) \\
(p<0.001)\end{array}$ \\
\hline Wang et al. (2011) [36] & RSV & $\begin{array}{l}\downarrow \text { TAOC } \\
\uparrow R O S\end{array}$ & $(p<0.01)$ & $\begin{array}{c}\uparrow \mathrm{TAOC} \\
\downarrow \text { ROS }\end{array}$ & $(p<0.01)$ \\
\hline Gaballah et al. (2016) [40] & RSV & $\begin{array}{c}\uparrow \mathrm{XO} \\
\uparrow \mathrm{PCC} \\
\downarrow \mathrm{GPx} \\
\uparrow \mathrm{Nrf-2} \text { DNA-binding activity }\end{array}$ & $(p<0.05)$ & $\begin{array}{c}\downarrow \mathrm{XO} \\
\downarrow \mathrm{PCC} \\
\uparrow \mathrm{GPx} \\
\uparrow \mathrm{Nrf-2} \text { DNA-binding activity }\end{array}$ & $(p<0.0001)$ \\
\hline Zhang et al. (2018) [43] & RSV & $\begin{array}{c}\uparrow \mathrm{ROS} \\
\uparrow \mathrm{MDA} \\
\downarrow \mathrm{SOD} \text { and CAT }\end{array}$ & $(p<0.01)$ & $\begin{array}{c}\downarrow \text { ROS } \\
\downarrow \mathrm{MDA} \\
\uparrow \mathrm{SOD} \text { and CAT }\end{array}$ & $(p<0.01)$ \\
\hline Palle et al. (2018) [42] & RSV & $\begin{array}{c}\downarrow \text { SDH } \\
\downarrow \mathrm{CS} \\
\downarrow \text { aconitase } \\
\downarrow \text { MC-I activity } \\
\downarrow \text { GSH } \\
\downarrow \text { CAT } \\
\uparrow \mathrm{MDA}\end{array}$ & $(p<0.05)$ & $\begin{array}{c}\uparrow \mathrm{SDH} \\
\uparrow \mathrm{CS} \\
\uparrow \text { aconitase } \\
\uparrow \mathrm{MC}-\mathrm{I} \text { activity } \\
\uparrow \mathrm{GSH} \\
\uparrow \mathrm{CAT} \\
\downarrow \mathrm{MDA}\end{array}$ & $(p<0.05)$ \\
\hline
\end{tabular}

Abbreviations: $\mathrm{BCP}, \beta$-caryophyllene; $\mathrm{CAT}$, catalase; $\mathrm{CS}$, citrate synthase; DHBA, dihydroxybenzoic acid; GPx, glutathione peroxidase; GR, glutathione reductase; GSH, glutathione; MC-I, mitochondrial complex I; MDA, malondialdehyde; NO, nitric oxide; PCC, protein carbonyl content; ROS, reactive oxygen species; RSV, resveratrol; SDH, succinate dehydrogenase; SOD, superoxide dismutase; TAOC, total antioxidant capacity; TBARS, thiobarbituric acid reactive substances; THC, $\Delta^{9}$-tetrahydrocannabinol; $\mathrm{XO}$, xanthine oxidase. 


\subsection{The effectiveness of CDCs or RSV to combat neuroinflammation}

Seven studies investigated the effects of RSV and CDCs on neuroinflammation in rodent brain tissue of the striatum and SNpc $[33,34,39,40,43,45,49]$. The results of these studies are summarized in Table 6 . Five studies showed increased markers of microglia and astrocytes activation via quantification of glial fibrillary acidic protein (GFAP) and ionized calcium-binding adaptor molecule 1 (Iba-1) protein or mRNA levels and these were significantly reduced via administration of THCV, BCP, or RSV [33,39,43,45,49]. Inflammatory protein markers and their complementary mRNA levels were significantly increased in the PD model groups and this was significantly countered with BCP or RSV treatment $[34,39,40,43,45,49]$. The suppressor of cytokine signalling protein 1 (SOCS-1) was detected in $\alpha$-synuclein transgenic mice and was signficantly upregulated by RSV treatment [45].

Table 6. Summary of biochemical and immunohistochemical analysis for inflammatory mediators in PD model groups and interventions. 


\begin{tabular}{|c|c|c|c|c|c|}
\hline & & Model Group (vs Control) & Significance & Group) & Significance \\
\hline \multirow{5}{*}{ Ojha et al. (2016) [39] } & \multirow{5}{*}{$\mathrm{BCP}$} & $\uparrow$ GFAP & \multirow{5}{*}{$(p<0.05)$} & $\downarrow$ GFAP & \multirow{5}{*}{$(p<0.05)$} \\
\hline & & $\uparrow I b a-1$ & & $\downarrow$ Iba-1 & \\
\hline & & $\uparrow \mathrm{IL}-1 \beta$ & & $\downarrow \mathrm{IL}-1 \beta$ & \\
\hline & & $\uparrow I L-6$ & & $\downarrow I L-6$ & \\
\hline & & $\uparrow \mathrm{TNF}-\alpha$ & & $\downarrow$ TNF- $\alpha$ & \\
\hline
\end{tabular}

\begin{tabular}{|c|c|c|c|c|c|}
\hline \multirow{5}{*}{$\begin{array}{l}\text { Viveros-Paredes et al. } \\
\qquad \text { (2017) [49] }\end{array}$} & \multirow{5}{*}{$\mathrm{BCP}$} & \multirow{5}{*}{$\begin{array}{c}\uparrow \text { GFAP-IR cells } \\
\uparrow \text { Iba-1-IR cells } \\
\uparrow I L-1 \beta \\
\uparrow I L-6 \\
\uparrow T \text { TNF- } \alpha\end{array}$} & \multirow{3}{*}{$\begin{array}{l}(p<0.01) \\
(p<0.05) \\
(p<0.01)\end{array}$} & \multirow{2}{*}{$\downarrow$ GFAP-IR cells } & \multirow{2}{*}{$(p<0.01)$} \\
\hline & & & & & \\
\hline & & & & $\downarrow I D A-1-\Pi K$ cenls & $(p<0.01)$ \\
\hline & & & $(p<0.05)$ & $\downarrow 1 L-1 \beta$ & $(p<0.01)$ \\
\hline & & & $(p<0.05)$ & $\downarrow 1 L-6$ & $(p<0.05)$ \\
\hline Garcia et al. (2011) [33] & THCV & $\uparrow$ microglial activation & $(p<0.005)$ & $\downarrow$ microglial activation & $(p<0.05)$ \\
\hline Jin et al. (2008) [34] & RSV & $\uparrow \mathrm{COX}-2$ & $(p<0.01)$ & $\downarrow \mathrm{COX}-2$ & $(p<0.01)$ \\
\hline & & $\uparrow$ TNF- $\alpha$ mRNA & & $\downarrow$ TNF- $\alpha$ mRNA & \\
\hline & & $\uparrow$ GFAP mRNA expression & $(p<0.01)$ & $\downarrow$ GFAP mRNA expression & $(p<0.01)$ \\
\hline & & $\uparrow C D 11$-immunoreactivity & $(p<0.01)$ & $\downarrow$ CD11-immunoreactivity & $(p<0.05)$ \\
\hline & & $\uparrow I L-1 \beta$ mRNA & $(p<0.01)$ & $\downarrow I L-1 \beta$ mRNA & $(p<0.01)$ \\
\hline Iofrumonto et al (2014) & & $\uparrow \mathrm{TNF}-\alpha$ mRNA & $(p<0.01)$ & $\downarrow$ TNF- $\alpha$ mRNA & $(p<0.05)$ \\
\hline Lor & RSV & $\uparrow I L-6$ mRNA & $(p<0.05)$ & $\downarrow$ IL-6 mRNA & $(p<0.01)$ \\
\hline & & $\uparrow I L-1 \beta$ R1 & $(p<0.05)$ & $\downarrow I L-1 \beta$ RI & $(p<0.05)$ \\
\hline & & $\uparrow \mathrm{TNF}-\alpha \mathrm{R} 1$ & $(p<0.05)$ & $\downarrow$ TNF- $\alpha$ RI & $(p<0.05)$ \\
\hline & & $\uparrow \mathrm{IL}-6 \mathrm{R} \alpha$ & $(p<0.01)$ & $\downarrow$ IL-6R $\alpha$ & $(p<0.05)$ \\
\hline & & $\downarrow$ SOCS- 1 & $(p<0.01)$ & $\uparrow S O C S-1$ & $(p<0.01)$ \\
\hline Gaballah et al. (2016) [40] & RSV & $\uparrow$ striatal IL- $1 \beta$ levels & $(p<0.05)$ & $\downarrow$ striatal IL- $1 \beta$ levels & $(p<0.05)$ \\
\hline & & $\uparrow$ GFAP & $(p<0.001)$ & $\downarrow$ GFAP & $(p<0.05)$ \\
\hline & & $\uparrow$ Iba-1 & $(p<0.001)$ & $\downarrow$ Iba-1 & $(p<0.01)$ \\
\hline Zhang et al. (2018) [43] & RSV & $\uparrow I L-1 \beta$ & $(p<0.01)$ & $\downarrow \mathrm{IL}-1 \beta$ & $(p<0.05)$ \\
\hline & & $\uparrow I L-6$ & $(p<0.001)$ & $\downarrow I L-6$ & $(p<0.05)$ \\
\hline & & $\uparrow \mathrm{TNF}-\alpha$ & $(p<0.05)$ & $\downarrow \mathrm{TNF}-\alpha$ & $(p<0.01)$ \\
\hline
\end{tabular}

Abbreviations: BCP, $\beta$-caryophyllene; COX-2, cyclooxygenase-2; GFAP, glial fibrillary acidic protein; GFAP-IR, glial fibrillary acidic protein immunoreactive cells; Iba-1, ionized calcium-binding adaptor molecule-1; Iba-1-IR, ionized calcium-binding adaptor molecule immunoreactive cells; IL-1 $\beta$, interleukin-1 beta; IL-1 $\beta$ R1, interleukin-1 beta receptor 1; IL-6, interleukin-6; IL-6R $\alpha$, interleukin-6 receptor alpha; RSV, resveratrol; TNF- $\alpha$, tumour necrosis factor-alpha; TNF- $\alpha$ R1, tumour necrosis factor-alpha receptor 1; SOCS-1, suppressor of cytokine signalling 1.

\subsection{RSV anti-apoptotic effects}

Four studies assessed the anti-apoptotic effects of RSV, there were no studies undertaken for the CDCs [36,37,40,44]. A summary of the RSV studies is included in Table 7. One study observed upregulation of apoptotic mediators in the PD model group that was decreased by RSV administration, with reduced neuronal apoptosis [36]. Procaspase and activated caspase-3 as key inducers of neuronal apoptosis were assessed by three studies, and all displayed increased caspase levels in PD model groups relative to controls [37,40,44]. Caspase levels were significantly decreased in groups receiving RSV treatment [37,40,44]. Bcl-2-associated X protein (Bax) and other pro-apoptotic regulators from the B-cell lymphoma 2 (Bcl-2) family were upregulated in PD model groups and were significantly reduced by RSV administration [37]. Increased p62 in nuclear factor kappa beta (NF- $k \beta)$ induced autophagy and increased acetylated microtubule-associated protein 1A/1B-light chain 3 (LC3-II) were countered with RSV treatment [44]. Increased $\mathrm{C} / \mathrm{EBP}$ homologous protein (CHOP) and glucose regulated protein (GRP78), both apoptotic markers of endoplasmic reticulum (ER) related oxidative stress, were significantly reduced by RSV treatment [40]. 
Table 7. Summary of biochemical and immunohistochemical analysis for markers of apoptosis PD model groups and interventions.

\begin{tabular}{|c|c|c|c|c|c|}
\hline Author \& Year & Intervention & $\begin{array}{c}\text { Apoptotic changes in PD Model } \\
\text { Group (vs Control) }\end{array}$ & $\begin{array}{c}\text { Level of } \\
\text { Significance }\end{array}$ & $\begin{array}{c}\text { Apoptotic changes in Main } \\
\text { Intervention Group (vs PD Model } \\
\text { Group) }\end{array}$ & $\begin{array}{c}\text { Level of } \\
\text { Significance }\end{array}$ \\
\hline Wang et al. (2011) [36] & RSV & $\downarrow$ apoptotic nigral cells & $(p<0.01)$ & $\downarrow$ apoptotic nigral cells & $(p<0.01)$ \\
\hline $\begin{array}{c}\text { Gaballah et al. (2016) } \\
{[40]}\end{array}$ & RSV & $\begin{array}{c}\uparrow \mathrm{CHOP} \text { and GRP78 } \\
\uparrow \text { striatal caspase-3 activity }\end{array}$ & $(p<0.05)$ & $\begin{array}{c}\downarrow \text { CHOP and GRP78 } \\
\downarrow \text { striatal caspase-3 activity }\end{array}$ & $(p<0.05)$ \\
\hline Huang et al. (2019) [37] & RSV & $\begin{array}{c}\uparrow \text { Bax } \\
\uparrow \text { activated caspase 3 } \\
\downarrow \text { Bcl-2 } \\
\downarrow \text { Pro-caspase-3 expression }\end{array}$ & $\begin{array}{l}(p<0.01) \\
(p<0.01) \\
(p<0.05) \\
(p<0.01)\end{array}$ & $\begin{array}{c}\downarrow \text { Bax } \\
\downarrow \text { activated caspase } 3 \\
\uparrow \text { Bcl-2 } \\
\uparrow \text { Pro-caspase-3 expression }\end{array}$ & $\begin{array}{l}(p<0.01) \\
(p<0.01) \\
(p<0.05) \\
(p<0.01)\end{array}$ \\
\hline
\end{tabular}

Abbreviations: Bax, Bcl-2-associated X protein; Bcl-2, B-cell lymphoma 2; CHOP, C/EBP homologous protein; GRP78, glucose regulated protein 78; LC3-II, microtubule-associated protein 1A/1B-light chain 3; RSV, resveratrol.

\subsection{Discussion}

This review considered the neuroprotective effects of CDCs and RSV for a range of neurotoxin-induced rodent PD models. Since degeneration of dopaminergic neurons (in the SNpc) is the key pathological hallmark of PD, quantitative analysis of dopamine levels and dopaminergic neurons was utilized as the main indicator for neuroprotection. The in vivo rodent studies supported the hypothesis that these agents were neuroprotective against PD, and resulted in increased dopamine and dopaminergic neuron levels in response to CDCs or RSV treatment, consistent with a recent meta-analysis [52]. Collectively, the molecular mechanisms associated with neuroprotection reflected anti-oxidative, anti-inflammatory and anti-apoptotic capabilities (Figure 2). 


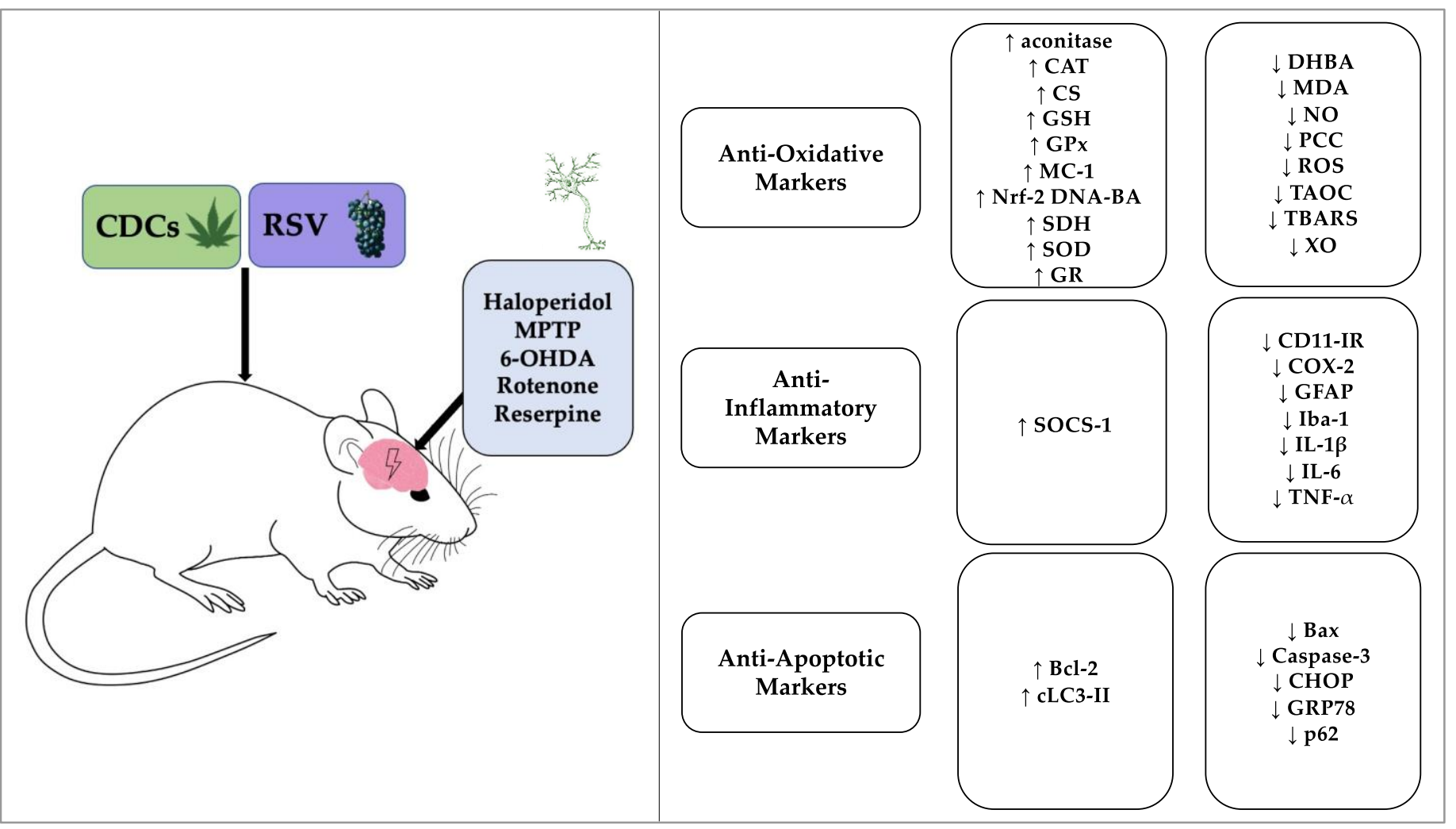

Figure 2. Schematic summary of the neuroprotective effects of CDCs or RSV following neurotoxin induction of PD in rodents.

Abbreviations: Bax, Bcl-2-associated X protein; Bcl-2, B-cell lymphoma 2; CAT, catalase; CD11-IR, CD11 immunoreactivity; CDCs, cannabis-dervided cannabinoids; CHOP, CCAAT/enhancer binding protein homologous protein; CS, citrate synthase; COX-2, cyclooxygenase-2; DHBA, dihydroxybenzoic acid; GFAP, glial fibrillary acidic protein; GPx, glutathione peroxidase; GR, glutathione reductase; GRP78, glucose-regulated protein 78; GSH, glutathione; 6-OHDA, 6-Hydroxydopamine; Iba-1, ionized calcium-binding adaptor molecule-1; IL-1 $\beta$, interleukin-1 beta; IL-6, interleukin-6; LC3-II, microtubule-associated protein 1A/1Blight chain 3; MC-1, mitochondrial complex 1; MDA, malondialdehyde;; MPTP, 1-methyl-4-phenyl-1,2,3,6-tetrahydropyridine; NO, nitric oxide; Nrf-2 DNA-BA, Nrf-2 DNA binding activity; PCC, protein carbonyl content; ROS, reactive oxygen species; RSV, resveratrol; SDH, succinate dehydrogenase; SOCS-1, suppressor of cytokine signalling-1; SOD, superoxide dismutase; TAOC, total antioxidant capacity; TBARS, thiobarbituric acid reactive substances; TNF- $\alpha$, tumour necrosis factor-alpha; XO, xanthine oxidase.

\subsection{Behavioural improvements indicative of neuroprotection}

The reduction in motor and cognitive functions in PD mice models were attributed to neurotoxin-induced dopaminergic neuron loss within the SNpc, resulting in a dysfunctional striatal pathway and overstimulation of GABAergic neurons innervating the thalamus [53]. Reduced interconnectivity between the cerebral cortex and basal ganglia results in an impairment of motor functions [54], and this was evidenced via reduced performance in rodent behavioural tests. Treatment with CDCs or RSV improved motor performance and reduced PD symptoms associated with bradykinesia, rigidity and postural control. Animals treated with neuroprotective agents displayed reduced catalepsy, reduction in abnormal behaviours and an overall improvement in movement, strength, speed or balance $[33-38,40-44,46,48,49]$. 


\subsection{Anti-oxidative effects of neuroprotective agents}

Neurons are vulnerable to oxidative damage but can mitigate redox stress through enzymatic and non-enzymatic defence mechanisms [55,56]. THC, BCP and RSV displayed anti-oxidative effects via reduced ROS, DHBA and NO production, with decreased MDA formation, lipid peroxidation and PCC, and restoration of tricarboxylic acid cycle enzyme activities [35,36,3840,42,43,46,48]. CDCs and RSV promoted upregulation of endogenous anti-oxidative enzymes and GSH levels to counter cellular redox stress, in part mediated via increased Nrf-2 activity [35,36,38,39,40,42,43,46]. However, Anandhan et al. [46] also reported reduced activity of SOD and CAT with RSV intervention.

\subsection{Anti-inflammatory effects of neuroprotective agents}

Neuroinflammation is likely to have a critical role in neurodegenerative diseases including PD [57]. Treatment with CDCs and RSV proved effective at reducing neuroinflammation in rodent PD models, as quantified by decreased levels of inflammatory protein markers and/or mRNA levels, as well as markers of astrocyte activation and microglia $[33,34,39,40,43,45,49]$. Collectively, beneficial anti-oxidative and anti-inflammatory effects of polyphenols including RSV, may in part relate to activity as free radical scavengers [58].

\subsection{Anti-apoptotic effects of RSV}

RSV displayed anti-apoptotic effects against nigral degeneration, with increased apoptotic markers Bcl-2 and pro-caspase 3 observed that paralleled decreased Bax and activated caspases [37,40,44]. The phosphoinositide 3-kinase (PI3K)/ protein kinase B (Akt) signalling pathway was upregulated by RSV to reduce dopaminergic neuron injury [37]. Akt is involved in homeostatic regulation and is recruited to cell plasma membranes in response to cell stress, where it is phosphorylated by PDK1 at serine-437 and threonine308 [59]. Akt activation can reduce Bax and activated caspase-3 levels to inhibit apoptosis. RSV treatment resulted in the upregulation of proteins involved in this pathway, and induced an increased p-Akt (ser437), PI3K-110 $\alpha$ and PDK-1 levels, thus inhibiting neuronal apoptosis in PD rodents [37]. Consistent with a role for Akt, reduced p-Akt was detected in dopaminergic neurons from the SN in PD patients after analysis of post-mortem brain tissue [60].

In addition to anti-apoptotic effects, RSV reduced neuronal degradation by induction of autophagy of misfolded $\alpha$-synuclein and p62 [44,61]. RSV treatment led to activated SIRT1, an NAD+ dependent deacetylase that deacetylates LC3-II intracellularly and results in increased cytoplasmic levels to break down $\alpha$-synuclein aggregates [44,61,62]. 
Endoplasmic reticulum (ER) stress occurs in response to an imbalance in ER homeostasis as a result of a prolonged accumulation of misfolded or damaged proteins such as $\alpha$-synuclein [63]. ER stress activates the unfolded protein response (UPR), and the apoptotic division of the UPR pathway contributes to the loss of striatal dopaminergic neurons in PD [63,64]. RSV treatment was able to reduce ER stress through downregulation of the glucose-regulated protein 78 (GRP78) and CCAAT/enhancer binding protein homologous protein (CHOP) [40,65]. GRP78 forms a complex with misfolded proteins, in turn initiating the UPR pathway. Overexpression of CHOP in ER stress stimulates the activation of the pro-apoptotic Bax protein facilitating activation of caspases. This may be one of the potential mechanisms influencing the beneficial descrease in apopotic nigral cells following RSV treatment in the rodent studies $[36,37,40,44]$.

\subsection{Pro-dopaminergic properties of CDC's may involve cannabinoid receptors}

THC is a major cannabinoid constituent of the Cannabis sativa plant and interacts with the G-protein coupled cannabinoid receptor 1 (CB1-R) and has a weak affinity for the cannabinoid receptor 2 (CB2-R) [66]. It might be expected that the attenuation of DA neuron loss in rodents would arise via stimulation of CB1 receptors in the CNS; however, a similar neuroprotective response was demonstrated using CBD [32], yet CBD has a low affinity for CB1 receptors. This suggests that the increase in TH-positive neurons and reduction in dopaminergic neuron loss can be mediated by a CB1-independent mechanism [32]. This was further supported by a demonstration that the minor phytocannabinoid THCV, which at low dose is a CB1R antagonist and a CB2R agonist, proved effective at countering a reduction in dopaminergic neuron levels with neuroprotective effects not attributed to CB1 binding, as a similar result was observed using a CBD derived drug [33]. Furthermore, the pro-dopaminergic action of THCV as a CB2 receptor agonist proved viable in an LPS-mediated inflammatory model of PD and demonstrated its anti-inflammatory potential for treatment in PD [33]. The stimulation of the CB1R by THC offers symptomatic relief against resting tremor in PD, but there are concerns regarding its ability to worsen hypokinesia and exhibit unwanted psychotropic effects [67]. In contrast, CBD is effective at attenuating dopaminergic neuron loss in a PD model [32] and may not induce the symptomatic complications associated with THC. Furthermore, the potentially beneficial immunomodulatory actions of cannabinoids such as CBD are assocaited with agonism to CB2 receptors [68].

\subsection{Clinical Trials using cannabinoids and RSV}

Although there is a growing body of evidence from preclinical animal studies that support the neuroprotective effects of CDCs and RSV, there remains a lack of human clinical trials that consider the effects of BCP, THC, THCV or RSV. There are, by contrast, several 
studies that have investigated the effects of CBD in PD and RSV in Alzheimer's disease (AD), with study characteristics summarised in Table 8. An open label dose-escalation study investigating the efficacy of CBD in individuals with PD reported that CBD administration improved motor movement and sleep quality, evidenced via increased Movement Disorder Society-Unified Parkinson's Disease Rating Scale (MDS-UPDRS) scores [69]. However, this small-scale trial provided evidence of adverse effects of CBD that included diarrhoea and hepatoxicity [69]. An exploratory double-blind trial investigating CBD reported no significant changes in movement scores, although there was an improvement in the Parkinson's Disease Questionnaire (PDQ) scores and overall emotional well-being [70]. A randomised, double-blind, placebo-controlled trial of RSV for patients with mild-to-moderate AD reported a decrease of some CSF immunomodulatory effects but was also without significant improvements in cognition [71,72]. A separate randomised, double-blind, placebo-controlled trial of RSV with glucose and malate displayed reduced neuropsychiatric deterioration in treatment groups; however, this improvement too remained insignificant [73]. Collectively, these studies have proved useful in evaluating safety of these compounds in patients with neurodegenerative diseases. However, evidence supporting the use of CBD and RSV in clinical treatment remains insufficient, and further human trials assessing the benefits of CDCs and RSV specifically for PD patients is required.

Table 8. Summary of clinical studies and human trial characteristics investigating the use of CBD or RSV in patients with neurodegenerative disease.

\begin{tabular}{|c|c|c|c|}
\hline Author \& Year & Study type & Population & Intervention \\
\hline $\begin{array}{l}\text { Leehey et al. (2020) [69] } \\
\text { NCT02818777 }\end{array}$ & $\begin{array}{c}\text { Safety and tolerability of CBD in } \\
\text { PD, open label dose-escalation } \\
\text { study }\end{array}$ & $\begin{array}{c}13 \text { participants, mean age } 68 \\
(\mathrm{SD}=6) \text { with } \mathrm{PD}\end{array}$ & $\begin{array}{c}\text { CBD: (Epidiolex®; } 100 \mathrm{mg} / \mathrm{mL} \text { ); } \\
5 \text { to } 20-25 \mathrm{mg} / \mathrm{kg} / \text { day; } 10-15 \\
\text { days }\end{array}$ \\
\hline $\begin{array}{c}\text { Chagas et al. (2014) [70] } \\
\text { NCT unavailable }\end{array}$ & $\begin{array}{l}\mathrm{CBD} \text { as a treatment for patients } \\
\text { with PD, exploratory double- } \\
\text { blind trial }\end{array}$ & 119 individuals; $P D$ & $\begin{array}{c}\text { CBD; } 75 \text { mg/day or CBD } 300 \\
\text { mg/day; } 36 \text { days }\end{array}$ \\
\hline $\begin{array}{l}\text { Turner et al. (2015) [71] } \\
\text { NCT0150484 }\end{array}$ & $\begin{array}{l}\text { Randomised, double-blind, } \\
\text { placebo-controlled trial of RSV }\end{array}$ & $\begin{array}{l}119 \text { individuals }>49 \text { with mild- } \\
\text { to-moderate AD }\end{array}$ & $\begin{array}{l}\text { 500-2000 mg RSV per day; } 52 \\
\text { weeks }\end{array}$ \\
\hline Moussa et al. (2017) [72] & $\begin{array}{l}\text { Retrospective study of Turner et } \\
\qquad \text { al. (2015) [73] }\end{array}$ & $\begin{array}{c}19 \text { CSF and plasma samples of } \\
\text { individuals with mild-to- } \\
\text { moderate AD }\end{array}$ & $\begin{array}{c}\text { 500-2000 mg RSV per day; } 52 \\
\text { weeks }\end{array}$ \\
\hline
\end{tabular}




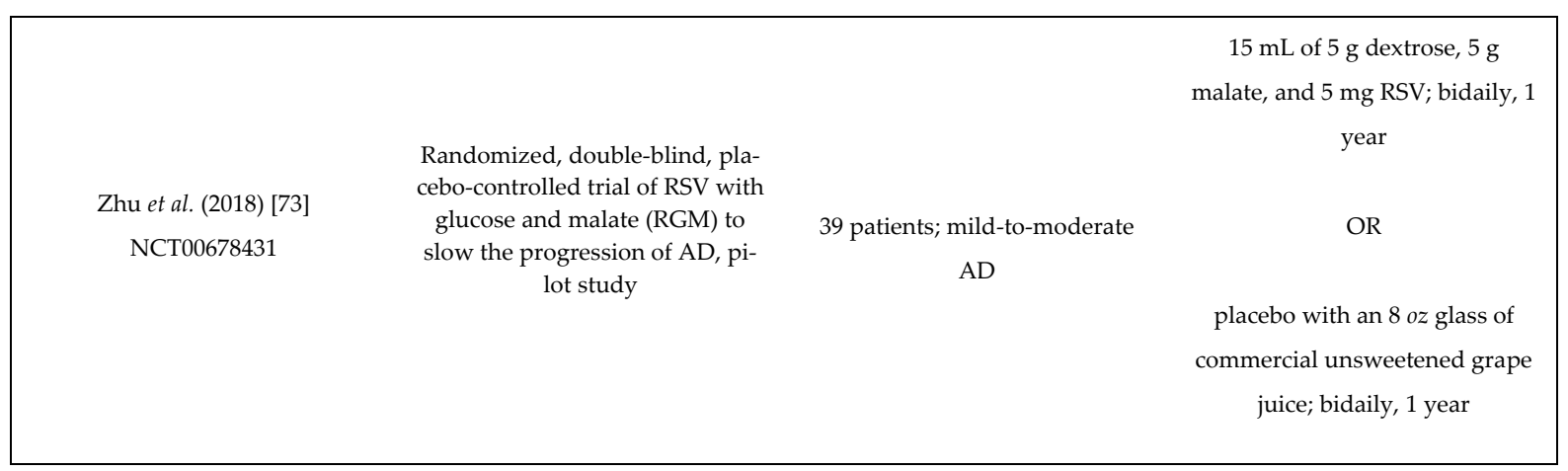

Abbreviations: AD, Alzheimer's Disease; CBD, cannabidiol; CSF, cerebrospinal fluid; NCT, National Clinical Trial; PD, Parkinson's disease; RGM, resveratrol glucose malate; SD, standard deviation.

\subsection{Bioavailability of CDCs and RSV}

The efficacy of CDCs and RSV has been demonstrated in rodent studies and data from clinical trials has supported the potential safety of CBD and RSV in humans. Nonetheless, compounds such as RSV have limitations associated with relatively rapid metabolism and low bioavailability, although this may be combatted by acute dose escalation and/or more chronic dosing regimens, or utilization of derivatives of RSV [74-78].

Details regarding the pharmacokinetics and bioavailability of CBD are limited, with a report of 31\% after smoking [79,80], however, when consumed orally, the bioavailability may only be as low as $6 \%[79,81]$. In accordance with CBD's lipophilic nature, it is often prescribed as oromucousal sprays or gel-encapsulations which utilize its oil/alcohol-soluble properties [79]. Moreover, the lipophilicity of CBD can be intentionally exploited when it is consumed, given that it can dissolve in high-fat nutrients to form micelle-structures favourable for gastrointestinal tract transport, thus increasing solubility and bioavailability [81]. However, whether these modifications result in increased bioavailability remains largely undetermined in humans, and also of concern is whether increased bioavailability impacts upon side effects, as short-term use of medicinal cannabinoids has a risk of non-serious adverse events and long-term use is as yet poorly characterized [82].

\subsection{Study Limitations}

A general limitation of the PD models described is that the neurotoxins used to induce PD phenotypes are fast-acting and cause a rapid depletion of dopaminergic neurons, typically within a period of several days, whereas in humans disease progression is much slower, and may take two decades for dopaminergic neuron depletion and establishment of clinical sequelae. Hence, although the described models have proved useful in establishing pharmacological effects of CDCs and RSV to combat PD pathology, the acute action of the neurotoxins will not replicate a long-term disease course and the associated symptomology observed in humans. Therefore, one cannot predict the extent of the protective effects of CDCs or RSV in the early-to-moderate stages of PD. Additionally, 
individual variability with respect to patient age, co-morbidities, and genetic influences on disease progression cannot be anticipated using rodent models. An extension of the length of studies may prove useful to better evaluate behavioural changes in motor and cognitive function in rodents, as well as increasing the validity of outcome measures.

There is also a risk of experimental and publication bias in these pre-clinical animal trials. For example, a lack of details concerning blinding in allocation and outcome assessments. Furthermore, all studies cited in this review only performed experiments with male rodents, and there may well be sex-specific differences in PD pathology. Lastly, although the majority of studies employed oral and intragastric administration,particularly for RSV, some of the studies used subcutaenous, intraperitoneal, or intravenous administration routes, ones less likely to be adopted routinely by humans, and that will also influence compound bioavailability and pharmacokinetic data.

\subsection{Conclusion}

To our knowledge, this is the first systematic review that has directly considered the effects of both selective CDCs and RSV in the neuroprotective treatment of PD. Collectively, in vivo rodent studies have demonstrated that these natural compounds are efficacious in their neuroprotection of PD and produced symptomatic benefits. However, there remains a need to expand these studies to a more chronic model and for additional studies that consider the benefits of formulations and derivatives with improved bioavailability, but ultimately, further human clinical trials are required with patients with early-stage or early-onset PD.

\section{References}

1. Xia, R.; Mao, Z.H. Progression of motor symptoms in Parkinson's disease. Neurosci Bull 2012, 28, 39-48, doi:10.1007/s12264012-1050-z.

2. Pringsheim, T.; Jette, N.; Frolkis, A.; Steeves, T.D. The prevalence of Parkinson's disease: a systematic review and metaanalysis. Mov Disord 2014, 29, 1583-1590, doi:10.1002/mds.25945.

3. Dorsey, E.R.; Sherer, T.; Okun, M.S.; Bloem, B.R. The Emerging Evidence of the Parkinson Pandemic. J Parkinsons Dis 2018, 8, S3-S8, doi:10.3233/JPD-181474.

4. Rocca, W.A. The burden of Parkinson's disease: a worldwide perspective. Lancet Neurol 2018, 17, 928-929, doi:10.1016/S14744422(18)30355-7.

5. Kouli, A.; Torsney, K.M.; Kuan, W.L. Parkinson's Disease: Etiology, Neuropathology, and Pathogenesis. In Parkinson's Disease: Pathogenesis and Clinical Aspects, Stoker, T.B., Greenland, J.C., Eds.; Codon Publications Copyright: The Authors.: Brisbane (AU), 2018.

6. $\quad$ Bloem, B.R.; Okun, M.S.; Klein, C. Parkinson's disease. Lancet 2021, 397, 2284-2303, doi:10.1016/S0140-6736(21)00218-X.

7. Beyer, K.; Domingo-Sàbat, M.; Ariza, A. Molecular pathology of Lewy body diseases. Int J Mol Sci 2009, 10, 724-745, doi:10.3390/ijms10030724.

8. Emamzadeh, F.N. Alpha-synuclein structure, functions, and interactions. J Res Med Sci 2016, 21, 29, doi:10.4103/17351995.181989.

9. Hindle, J.V. Ageing, neurodegeneration and Parkinson's disease. Age Ageing 2010, 39, 156-161, doi:10.1093/ageing/afp223. 
10. Lill, C.M.; Klein, C. [Epidemiology and causes of Parkinson's disease]. Nervenarzt 2017, 88, 345-355, doi:10.1007/s00115-0170288-0.

11. Johnson, C.C.; Gorell, J.M.; Rybicki, B.A.; Sanders, K.; Peterson, E.L. Adult nutrient intake as a risk factor for Parkinson's disease. Int J Epidemiol 1999, 28, 1102-1109, doi:10.1093/ije/28.6.1102.

12. Klein, C.; Westenberger, A. Genetics of Parkinson's disease. Cold Spring Harb Perspect Med 2012, 2, a008888, doi:10.1101/cshperspect.a008888.

13. Koller, W.C.; Rueda, M.G. Mechanism of action of dopaminergic agents in Parkinson's disease. Neurology 1998, 50, S11-14; discussion S44-18, doi:10.1212/wnl.50.6_suppl_6.s11.

14. Hauser, R.A. Levodopa: past, present, and future. Eur Neurol 2009, 62, 1-8, doi:10.1159/000215875.

15. Jankovic, J.; Aguilar, L.G. Current approaches to the treatment of Parkinson's disease. Neuropsychiatr Dis Treat 2008, 4, 743757, doi:10.2147/ndt.s2006.

16. Riederer, P.; Laux, G. MAO-inhibitors in Parkinson's Disease. Exp Neurobiol 2011, 20, 1-17, doi:10.5607/en.2011.20.1.1.

17. Youdim, M.B.; Lavie, L. Selective MAO-A and B inhibitors, radical scavengers and nitric oxide synthase inhibitors in Parkinson's disease. Life Sci 1994, 55, 2077-2082, doi:10.1016/0024-3205(94)00388-2.

18. Aryal, S.; Skinner, T.; Bridges, B.; Weber, J.T. The Pathology of Parkinson's Disease and Potential Benefit of Dietary Polyphenols. Molecules 2020, 25, doi:10.3390/molecules25194382.

19. Nair, M.P.; Figueroa, G.; Casteleiro, G.; Muñoz, K.; Agudelo, M. Alcohol Versus Cannabinoids: A Review of Their Opposite Neuro-Immunomodulatory Effects and Future Therapeutic Potentials. J Alcohol Drug Depend 2015, 3, doi:10.4172/23296488.1000184 .

20. Caruana, M.; Cauchi, R.; Vassallo, N. Putative Role of Red Wine Polyphenols against Brain Pathology in Alzheimer's and Parkinson's Disease. Front Nutr 2016, 3, 31, doi:10.3389/fnut.2016.00031.

21. Russo, E.B. History of cannabis and its preparations in saga, science, and sobriquet. Chem Biodivers 2007, 4, 1614-1648, doi:10.1002/cbdv.200790144.

22. Mouhamed, Y.; Vishnyakov, A.; Qorri, B.; Sambi, M.; Frank, S.S.; Nowierski, C.; Lamba, A.; Bhatti, U.; Szewczuk, M.R. Therapeutic potential of medicinal marijuana: an educational primer for health care professionals. Drug Healthc Patient Saf 2018, 10, 45-66, doi:10.2147/DHPS.S158592.

23. Pertwee, R.G. The diverse CB1 and CB2 receptor pharmacology of three plant cannabinoids: delta9-tetrahydrocannabinol, cannabidiol and delta9-tetrahydrocannabivarin. Br J Pharmacol 2008, 153, 199-215, doi:10.1038/sj.bjp.0707442.

24. Gertsch, J.; Leonti, M.; Raduner, S.; Racz, I.; Chen, J.Z.; Xie, X.Q.; Altmann, K.H.; Karsak, M.; Zimmer, A. Beta-caryophyllene is a dietary cannabinoid. Proc Natl Acad Sci U S A 2008, 105, 9099-9104, doi:10.1073/pnas.0803601105.

25. Romano, B.; Pagano, E.; Orlando, P.; Capasso, R.; Cascio, M.G.; Pertwee, R.; Marzo, V.D.; Izzo, A.A.; Borrelli, F. Pure $\Delta^{9}-$ tetrahydrocannabivarin and a Cannabis sativa extract with high $\Delta^{9}$-tetrahydrocannabivarin inhibit nitrite production in murine peritoneal macrophages. Pharmacol Res 2016, 113, 199-208, doi:10.1016/j.phrs.2016.07.045.

26. Yang, M.; Lv, Y.; Tian, X.; Lou, J.; An, R.; Zhang, Q.; Li, M.; Xu, L.; Dong, Z. Neuroprotective Effect of $\beta$-Caryophyllene on Cerebral Ischemia-Reperfusion Injury via Regulation of Necroptotic Neuronal Death and Inflammation:. Front Neurosci 2017, 11, 583, doi:10.3389/fnins.2017.00583.

27. Ramírez-Garza, S.L.; Laveriano-Santos, E.P.; Marhuenda-Muñoz, M.; Storniolo, C.E.; Tresserra-Rimbau, A.; VallverdúQueralt, A.; Lamuela-Raventós, R.M. Health Effects of Resveratrol: Results from Human Intervention Trials. Nutrients 2018, 10, doi:10.3390/nu10121892.

28. Salehi, B.; Mishra, A.P.; Nigam, M.; Sener, B.; Kilic, M.; Sharifi-Rad, M.; Fokou, P.V.T.; Martins, N.; Sharifi-Rad, J. Resveratrol: A Double-Edged Sword in Health Benefits. Biomedicines 2018, 6, doi:10.3390/biomedicines6030091. 
29. Zhang, H.; Li, C.; Kwok, S.T.; Zhang, Q.W.; Chan, S.W. A Review of the Pharmacological Effects of the Dried Root of Polygonum cuspidatum (Hu Zhang) and Its Constituents. Evid Based Complement Alternat Med 2013, 2013, 208349, doi:10.1155/2013/208349.

30. Moher, D.; Liberati, A.; Tetzlaff, J.; Altman, D.G.; Group, P. Preferred reporting items for systematic reviews and metaanalyses: the PRISMA statement. J Clin Epidemiol 2009, 62, 1006-1012, doi:10.1016/j.jclinepi.2009.06.005.

31. Hooijmans, C.R.; Rovers, M.M.; de Vries, R.B.; Leenaars, M.; Ritskes-Hoitinga, M.; Langendam, M.W. SYRCLE's risk of bias tool for animal studies. BMC Med Res Methodol 2014, 14, 43, doi:10.1186/1471-2288-14-43.

32. Lastres-Becker, I.; Molina-Holgado, F.; Ramos, J.A.; Mechoulam, R.; Fernández-Ruiz, J. Cannabinoids provide neuroprotection against 6-hydroxydopamine toxicity in vivo and in vitro: relevance to Parkinson's disease. Neurobiol Dis 2005, 19, 96-107, doi:10.1016/j.nbd.2004.11.009.

33. García, C.; Palomo-Garo, C.; García-Arencibia, M.; Ramos, J.; Pertwee, R.; Fernández-Ruiz, J. Symptom-relieving and neuroprotective effects of the phytocannabinoid $\Delta^{9}$-THCV in animal models of Parkinson's disease. Br J Pharmacol 2011, 163, 1495-1506, doi:10.1111/j.1476-5381.2011.01278.x.

34. Jin, F.; Wu, Q.; Lu, Y.F.; Gong, Q.H.; Shi, J.S. Neuroprotective effect of resveratrol on 6-OHDA-induced Parkinson's disease in rats. Eur J Pharmacol 2008, 600, 78-82, doi:10.1016/j.ejphar.2008.10.005.

35. Khan, M.M.; Ahmad, A.; Ishrat, T.; Khan, M.B.; Hoda, M.N.; Khuwaja, G.; Raza, S.S.; Khan, A.; Javed, H.; Vaibhav, K.; et al. Resveratrol attenuates 6-hydroxydopamine-induced oxidative damage and dopamine depletion in rat model of Parkinson's disease. Brain Res 2010, 1328, 139-151, doi:10.1016/j.brainres.2010.02.031.

36. Wang, Y.; Xu, H.; Fu, Q.; Ma, R.; Xiang, J. Protective effect of resveratrol derived from Polygonum cuspidatum and its liposomal form on nigral cells in parkinsonian rats. J Neurol Sci 2011, 304, 29-34, doi:10.1016/j.jns.2011.02.025.

37. Huang, N.; Zhang, Y.; Chen, M.; Jin, H.; Nie, J.; Luo, Y.; Zhou, S.; Shi, J.; Jin, F. Resveratrol delays 6-hydroxydopamineinduced apoptosis by activating the PI3K/Akt signaling pathway. Exp Gerontol 2019, 124, 110653, doi:10.1016/j.exger.2019.110653.

38. Abdel-Salam, O.M.; El-Sayed El-Shamarka, M.; Salem, N.A.; El-Din M Gaafar, A. Effects of Cannabis sativa extract on haloperidol-induced catalepsy and oxidative stress in the mice. EXCLI J 2012, 11, 45-58.

39. Ojha, S.; Javed, H.; Azimullah, S.; Haque, M.E. $\beta$-Caryophyllene, a phytocannabinoid attenuates oxidative stress, neuroinflammation, glial activation, and salvages dopaminergic neurons in a rat model of Parkinson disease. Mol Cell Biochem 2016, 418, 59-70, doi:10.1007/s11010-016-2733-y.

40. Gaballah, H.H.; Zakaria, S.S.; Elbatsh, M.M.; Tahoon, N.M. Modulatory effects of resveratrol on endoplasmic reticulum stress-associated apoptosis and oxido-inflammatory markers in a rat model of rotenone-induced Parkinson's disease. Chem Biol Interact 2016, 251, 10-16, doi:10.1016/j.cbi.2016.03.023.

41. Peres, F.F.; Levin, R.; Suiama, M.A.; Diana, M.C.; Gouvêa, D.A.; Almeida, V.; Santos, C.M.; Lungato, L.; Zuardi, A.W.; Hallak, J.E.; et al. Cannabidiol Prevents Motor and Cognitive Impairments Induced by Reserpine in Rats. Front Pharmacol 2016, 7 , 343, doi:10.3389/fphar.2016.00343.

42. Palle, S.; Neerati, P. Improved neuroprotective effect of resveratrol nanoparticles as evinced by abrogation of rotenoneinduced behavioral deficits and oxidative and mitochondrial dysfunctions in rat model of Parkinson's disease. Naunyn Schmiedebergs Arch Pharmacol 2018, 391, 445-453, doi:10.1007/s00210-018-1474-8.

43. Zhang, L.F.; Yu, X.L.; Ji, M.; Liu, S.Y.; Wu, X.L.; Wang, Y.J.; Liu, R.T. Resveratrol alleviates motor and cognitive deficits and neuropathology in the A53T $\alpha$-synuclein mouse model of Parkinson's disease. Food Funct 2018, 9, 6414-6426, doi:10.1039/c8fo00964c.

44. Guo, Y.J.; Dong, S.Y.; Cui, X.X.; Feng, Y.; Liu, T.; Yin, M.; Kuo, S.H.; Tan, E.K.; Zhao, W.J.; Wu, Y.C. Resveratrol alleviates MPTP-induced motor impairments and pathological changes by autophagic degradation of $\alpha$-synuclein via SIRT1deacetylated LC3. Mol Nutr Food Res 2016, 60, 2161-2175, doi:10.1002/mnfr.201600111. 
45. Lofrumento, D.D.; Nicolardi, G.; Cianciulli, A.; De Nuccio, F.; La Pesa, V.; Carofiglio, V.; Dragone, T.; Calvello, R.; Panaro, M.A. Neuroprotective effects of resveratrol in an MPTP mouse model of Parkinson's-like disease: possible role of SOCS-1 in reducing pro-inflammatory responses. Innate Immun 2014, 20, 249-260, doi:10.1177/1753425913488429.

46. Anandhan, A.; Tamilselvam, K.; Vijayraja, D.; Ashokkumar, N.; Rajasankar, S.; Manivasagam, T. Resveratrol attenuates oxidative stress and improves behaviour in 1 -methyl-4-phenyl-1,2,3,6-tetrahydropyridine (MPTP) challenged mice. Ann Neurosci 2010, 17, 113-119, doi:10.5214/ans.0972-7531.1017304.

47. Xia, D.; Sui, R.; Zhang, Z. Administration of resveratrol improved Parkinson's disease-like phenotype by suppressing apoptosis of neurons via modulating the MALAT1/miR-129/SNCA signaling pathway. J Cell Biochem 2019, 120, 4942-4951, doi:10.1002/jcb.27769.

48. Lu, K.T.; Ko, M.C.; Chen, B.Y.; Huang, J.C.; Hsieh, C.W.; Lee, M.C.; Chiou, R.Y.; Wung, B.S.; Peng, C.H.; Yang, Y.L. Neuroprotective effects of resveratrol on MPTP-induced neuron loss mediated by free radical scavenging. J Agric Food Chem 2008, 56, 6910-6913, doi:10.1021/jf8007212.

49. Viveros-Paredes, J.M.; González-Castañeda, R.E.; Gertsch, J.; Chaparro-Huerta, V.; López-Roa, R.I.; Vázquez-Valls, E.; BeasZarate, C.; Camins-Espuny, A.; Flores-Soto, M.E. Neuroprotective Effects of $\beta$-Caryophyllene against Dopaminergic Neuron Injury in a Murine Model of Parkinson's Disease Induced by MPTP. Pharmaceuticals (Basel) 2017, 10, doi:10.3390/ph10030060. Amende, I.; Kale, A.; McCue, S.; Glazier, S.; Morgan, J.P.; Hampton, T.G. Gait dynamics in mouse models of Parkinson's disease and Huntington's disease. J Neuroeng Rehabil 2005, 2, 20, doi:10.1186/1743-0003-2-20.

51. Ungerstedt, U.; Arbuthnott, G.W. Quantitative recording of rotational behavior in rats after 6-hydroxy-dopamine lesions of the nigrostriatal dopamine system. Brain Res 1970, 24, 485-493, doi:10.1016/0006-8993(70)90187-3.

52. Su, C.F.; Jiang, L.; Zhang, X.W.; Iyaswamy, A.; Li, M. Resveratrol in Rodent Models of Parkinson's Disease: A Systematic Review of Experimental Studies. Front Pharmacol 2021, 12, 644219, doi:10.3389/fphar.2021.644219.

53. Mallet, N.; Delgado, L.; Chazalon, M.; Miguelez, C.; Baufreton, J. Cellular and Synaptic Dysfunctions in Parkinson's Disease: Stepping out of the Striatum. Cells 2019, 8, doi:10.3390/cells8091005.

54. Rubin, J.E.; McIntyre, C.C.; Turner, R.S.; Wichmann, T. Basal ganglia activity patterns in parkinsonism and computational modeling of their downstream effects. Eur J Neurosci 2012, 36, 2213-2228, doi:10.1111/j.1460-9568.2012.08108.x.

55. Lee, K.H.; Cha, M.; Lee, B.H. Neuroprotective Effect of Antioxidants in the Brain. Int J Mol Sci 2020, 21, doi:10.3390/ijms21197152.

56. Smeyne, M.; Smeyne, R.J. Glutathione metabolism and Parkinson's disease. Free Radic Biol Med 2013, 62, 13-25, doi:10.1016/j.freeradbiomed.2013.05.001.

57. Gelders, G.; Baekelandt, V.; Van der Perren, A. Linking Neuroinflammation and Neurodegeneration in Parkinson's Disease. J Immunol Res 2018, 2018, 4784268, doi:10.1155/2018/4784268.

58. de Sá Coutinho, D.; Pacheco, M.T.; Frozza, R.L.; Bernardi, A. Anti-Inflammatory Effects of Resveratrol: Mechanistic Insights. Int J Mol Sci 2018, 19, doi:10.3390/ijms19061812.

59. Vanhaesebroeck, B.; Alessi, D.R. The PI3K-PDK1 connection: more than just a road to PKB. Biochem J 2000, 346 Pt 3, $561-576$.

60. Malagelada, C.; Jin, Z.H.; Greene, L.A. RTP801 is induced in Parkinson's disease and mediates neuron death by inhibiting Akt phosphorylation/activation. J Neurosci 2008, 28, 14363-14371, doi:10.1523/JNEUROSCI.3928-08.2008.

61. Wu, Y.; Li, X.; Zhu, J.X.; Xie, W.; Le, W.; Fan, Z.; Jankovic, J.; Pan, T. Resveratrol-activated AMPK/SIRT1/autophagy in cellular models of Parkinson's disease. Neurosignals 2011, 19, 163-174, doi:10.1159/000328516.

62. Lee, I.H. Mechanisms and disease implications of sirtuin-mediated autophagic regulation. Exp Mol Med 2019, 51, 1-11, doi:10.1038/s12276-019-0302-7.

63. Colla, E. Linking the Endoplasmic Reticulum to Parkinson's Disease and Alpha-Synucleinopathy. Front Neurosci 2019, 13, 560, doi:10.3389/fnins.2019.00560. 
64. Hoozemans, J.J.; van Haastert, E.S.; Nijholt, D.A.; Rozemuller, A.J.; Scheper, W. Activation of the unfolded protein response is an early event in Alzheimer's and Parkinson's disease. Neurodegener Dis 2012, 10, 212-215, doi:10.1159/000334536.

65. Gorbatyuk, M.S.; Shabashvili, A.; Chen, W.; Meyers, C.; Sullivan, L.F.; Salganik, M.; Lin, J.H.; Lewin, A.S.; Muzyczka, N.; Gorbatyuk, O.S. Glucose regulated protein 78 diminishes $\alpha$-synuclein neurotoxicity in a rat model of Parkinson disease. Mol Ther 2012, 20, 1327-1337, doi:10.1038/mt.2012.28.

66. Lu, H.C.; Mackie, K. An Introduction to the Endogenous Cannabinoid System. Biol Psychiatry 2016, 79, 516-525, doi:10.1016/j.biopsych.2015.07.028.

67. Buhmann, C.; Mainka, T.; Ebersbach, G.; Gandor, F. Evidence for the use of cannabinoids in Parkinson's disease. J Neural Transm (Vienna) 2019, 126, 913-924, doi:10.1007/s00702-019-02018-8.

68. Turcotte, C.; Blanchet, M.R.; Laviolette, M.; Flamand, N. The CB2 receptor and its role as a regulator of inflammation. Cell Mol Life Sci 2016, 73, 4449-4470, doi:10.1007/s00018-016-2300-4.

69. Leehey, M.A.; Liu, Y.; Hart, F.; Epstein, C.; Cook, M.; Sillau, S.; Klawitter, J.; Newman, H.; Sempio, C.; Forman, L.; et al. Safety and Tolerability of Cannabidiol in Parkinson Disease: An Open Label, Dose-Escalation Study. Cannabis Cannabinoid Res 2020, 5, 326-336, doi:10.1089/can.2019.0068.

70. Chagas, M.H.; Zuardi, A.W.; Tumas, V.; Pena-Pereira, M.A.; Sobreira, E.T.; Bergamaschi, M.M.; dos Santos, A.C.; Teixeira, A.L.; Hallak, J.E.; Crippa, J.A. Effects of cannabidiol in the treatment of patients with Parkinson's disease: an exploratory double-blind trial. J Psychopharmacol 2014, 28, 1088-1098, doi:10.1177/0269881114550355.

71. Turner, R.S.; Thomas, R.G.; Craft, S.; van Dyck, C.H.; Mintzer, J.; Reynolds, B.A.; Brewer, J.B.; Rissman, R.A.; Raman, R.; Aisen, P.S.; et al. A randomized, double-blind, placebo-controlled trial of resveratrol for Alzheimer disease. Neurology 2015, 85, 1383-1391, doi:10.1212/WNL.0000000000002035.

Moussa, C.; Hebron, M.; Huang, X.; Ahn, J.; Rissman, R.A.; Aisen, P.S.; Turner, R.S. Resveratrol regulates neuroinflammation and induces adaptive immunity in Alzheimer's disease. J Neuroinflammation 2017, 14, 1, doi:10.1186/s12974016-0779-0.

73. Zhu, C.W.; Grossman, H.; Neugroschl, J.; Parker, S.; Burden, A.; Luo, X.; Sano, M. A randomized, double-blind, placebocontrolled trial of resveratrol with glucose and malate (RGM) to slow the progression of Alzheimer's disease: A pilot study. Alzheimers Dement (N Y) 2018, 4, 609-616, doi:10.1016/j.trci.2018.09.009.

74. Gambini, J.; Inglés, M.; Olaso, G.; Lopez-Grueso, R.; Bonet-Costa, V.; Gimeno-Mallench, L.; Mas-Bargues, C.; Abdelaziz, K.M.; Gomez-Cabrera, M.C.; Vina, J.; et al. Properties of Resveratrol: In Vitro and In Vivo Studies about Metabolism, Bioavailability, and Biological Effects in Animal Models and Humans. Oxid Med Cell Longev 2015, 2015, 837042, doi:10.1155/2015/837042.

75. Chimento, A.; De Amicis, F.; Sirianni, R.; Sinicropi, M.S.; Puoci, F.; Casaburi, I.; Saturnino, C.; Pezzi, V. Progress to Improve Oral Bioavailability and Beneficial Effects of Resveratrol. Int J Mol Sci 2019, 20, doi:10.3390/ijms20061381.

76. Walle, T. Bioavailability of resveratrol. Ann N Y Acad Sci 2011, 1215, 9-15, doi:10.1111/j.1749-6632.2010.05842.x.

77. Almeida, L.; Vaz-da-Silva, M.; Falcão, A.; Soares, E.; Costa, R.; Loureiro, A.I.; Fernandes-Lopes, C.; Rocha, J.F.; Nunes, T.; Wright, L.; et al. Pharmacokinetic and safety profile of trans-resveratrol in a rising multiple-dose study in healthy volunteers. Mol Nutr Food Res 2009, 53 Suppl 1, S7-15, doi:10.1002/mnfr.200800177.

78. Boocock, D.J.; Faust, G.E.; Patel, K.R.; Schinas, A.M.; Brown, V.A.; Ducharme, M.P.; Booth, T.D.; Crowell, J.A.; Perloff, M.; Gescher, A.J.; et al. Phase I dose escalation pharmacokinetic study in healthy volunteers of resveratrol, a potential cancer chemopreventive agent. Cancer Epidemiol Biomarkers Prev 2007, 16, 1246-1252, doi:10.1158/1055-9965.EPI-07-0022.

79. Millar, S.A.; Stone, N.L.; Yates, A.S.; O'Sullivan, S.E. A Systematic Review on the Pharmacokinetics of Cannabidiol in Humans. Front Pharmacol 2018, 9, 1365, doi:10.3389/fphar.2018.01365. 
80. Ohlsson, A.; Lindgren, J.E.; Andersson, S.; Agurell, S.; Gillespie, H.; Hollister, L.E. Single-dose kinetics of deuterium-labelled cannabidiol in man after smoking and intravenous administration. Biomed Environ Mass Spectrom 1986, 13, 77-83, doi:10.1002/bms.1200130206.

81. Perucca, E.; Bialer, M. Critical Aspects Affecting Cannabidiol Oral Bioavailability and Metabolic Elimination, and Related Clinical Implications. CNS Drugs 2020, 34, 795-800, doi:10.1007/s40263-020-00741-5.

82. Wang, T.; Collet, J.P.; Shapiro, S.; Ware, M.A. Adverse effects of medical cannabinoids: a systematic review. CMAJ 2008, 178, 1669-1678, doi:10.1503/cmaj.071178. 